\title{
The risk of tuberculosis related to tumour necrosis factor antagonist therapies: a TBNET consensus statement
}

\author{
I. Solovic, M. Sester, J.J. Gomez-Reino, H.L. Rieder, S. Ehlers, H.J. Milburn, \\ B. Kampmann, B. Hellmich, R. Groves, S. Schreiber, R.S. Wallis, G. Sotgiu, \\ E.H. Schölvinck, D. Goletti, J.P. Zellweger, R. Diel, L. Carmona, F. Bartalesi, P. Ravn, \\ A. Bossink, R. Duarte, C. Erkens, J. Clark, G.B. Migliori and C. Lange
}

ABSTRACT: Anti-tumour necrosis factor (TNF) monoclonal antibodies or soluble TNF receptors have become an invaluable treatment against chronic inflammatory diseases, such as rheumatoid arthritis, inflammatory bowel disease and psoriasis. Individuals who are treated with TNF antagonists are at an increased risk of reactivating latent infections, especially tuberculosis (TB).

Following TNF antagonist therapy, the relative risk for TB is increased up to 25 times, depending on the clinical setting and the TNF antagonist used. Interferon- $\gamma$ release assays or, as an alternative in individuals without a history of bacille Calmette-Guérin vaccination, tuberculin skin testing is recommended to screen all adult candidates for TNF antagonist treatment for the presence of latent infection with Mycobacterium tuberculosis.

Moreover, paediatric practice suggests concomitant use of both the tuberculin skin test and an interferon- $\gamma$ release assay, as there are insufficient data in children to recommend one test over the other. Consequently, targeted preventive chemotherapy is highly recommended for all individuals with persistent $M$. tuberculosis-specific immune responses undergoing TNF antagonist therapy as it significantly reduces the risk of progression to TB.

This TBNET consensus statement summarises current knowledge and expert opinions and provides evidence-based recommendations to reduce the TB risk among candidates for TNF antagonist therapy.

KEYWORDS: Interferon- $\gamma$ release assay, tuberculin skin test, tuberculosis, tumour necrosis factor

$\mathbf{T}$ umour necrosis factor (TNF) and TNF receptors play a key role in mediating immune responses in acute and chronic inflammation [1-3]. Over the past decade, TNF antagonists in the form of anti-TNF monoclonal antibodies or TNF fusion protein have become an invaluable treatment against chronic inflammatory diseases, such as rheumatoid arthritis, psoriasis and psoriatic arthritis, ankylosing spondylitis, juvenile idiopathic arthritis and inflammatory bowel disease [4-7].

Tuberculosis (TB) is a granulomatous disease caused by infection with Mycobacterium tuberculosis.
Most of the individuals who are thought to have become infected with $M$. tuberculosis will never develop TB due to the control exercised by the host immune system $[8,9]$. One of the key cytokines in the immune response against infection with $M$. tuberculosis is TNF, which is also critical for the integrity of the granuloma [10]. Individuals who are being treated with anti-TNF therapies are at increased risk of developing TB. Following TNF antagonist therapy, the relative risk for $\mathrm{TB}$ is increased 1.6-25.1 times, depending on the clinical setting and the TNF antagonist used $[4,7,11,12]$. The majority of cases of TB related to TNF antagonist therapies occur in close temporal proximity to

Previous articles in this Series: No. 1: Erkens CGM, Kamphorst M, Abubakar I, et al. Tuberculosis contact investigation in low prevalence countries: a European consensus. Eur Respir J 2010; 36: 925-949.

AFFLIATIONS

For a full list of affiliations refer to the Acknowledgements section

CORRESPONDENCE

C. Lange

Division of Clinical Infectious

Diseases, Medical Clinic

Research Center Borstel

Parkallee 35

23845 Borstel

Germany

E-mail: clange@fz-borstel.de

Received:

Feb 212010

Accepted after revision:

May 172010

First published online:

June 072010

TBNET is a Clinical Research Collaboration of the European Respiratory Society. 
treatment initiation with TNF antagonists $[7,13]$ and reactivation of latent infection with $M$. tuberculosis shows characteristically rapid progression.

Preventive chemotherapy can substantially reduce the incidence of TB in individuals with latent infection, who are being identified by positive $M$. tuberculosis specific immune responses either by the tuberculin skin test or an in vitro interferon- $\gamma$ release assay (IGRA).

In the only prospective cohort study to date that evaluated the effect of prevention of TB in individuals undergoing TNF antagonist therapies, the risk in individuals who exhibited positive immune responses in a two-step tuberculin skin test prior to TNF antagonist therapies could be dramatically reduced by 9 months isoniazid preventive therapy [14]. However, this effect was only apparent in those who were compliant with preventive therapy.

Recently, IGRAs have been introduced for the diagnosis of latent infection with $M$. tuberculosis. The sensitivity of IGRA for the detection of latent infection is generally superior to the tuberculin skin test $[15,16]$ and is most apparent in immunocompromised individuals [17]. With a few exceptions, immune responses that are assayed through the IGRAs are not affected by infections of non-tuberculous mycobacteria. Importantly, antigens that elicit immune responses in IGRAs are absent in Mycobacterium bovis bacille Calmette-Guérin (BCG) and consequently IGRAs have superior specificity for $M$. tuberculosis infection compared to the tuberculin skin test in individuals with a history of BCG vaccination $[15,16]$. The positive predictive value of an IGRA result for the development of $\mathrm{TB}$ is accordingly superior compared to that of a tuberculin skin test [18].

Because of the superior performance of IGRAs for the diagnosis of latent infection with $M$. tuberculosis in general, national guidelines for screening prior to TNF antagonist therapies in Germany [19] and Switzerland [20] advocate the use of IGRAs in this situation. However, IGRAs are not universally available and it is currently unclear whether they are superior to the tuberculin skin test in identifying individuals at risk of TB following TNF antagonist therapy who should be offered preventive therapy.

There is substantial uncertainty among clinicians about the management of patients undergoing TNF antagonist therapies and the best strategies for the prevention of TB. As international guidelines do not currently exist on this topic and clinical decisions have to rely on expert opinions, this document by a TBNET consensus group summarises the current knowledge of the risk of TB following TNF antagonist therapies and provides evidence graded recommendations (evidence categories A-D) (table 1) for the screening for latent infection with $M$. tuberculosis and for preventive chemotherapies in individuals undergoing TNF antagonist therapies.

\section{TNF AND TNF ANTAGONIST THERAPIES: MODE OF ACTION AND SIDE-EFFECTS \\ TNF biology}

TNF and TNF receptors are important regulators of immune cell activation, proliferation, differentiation, survival and apoptosis [1-3]. TNF is produced as a transmembrane protein (tmTNF) which is cleaved by a metalloproteinase (TACE) to a soluble form (sTNF). TNF associates to a homotrimer which binds to cell surface TNFR1 and TNFR2. TNFR2 is fully activated by tmTNF but not by sTNF. TNFR1 signals via death domain caspase-dependent pathways and induces apoptosis. Both TNFR1 and TNFR2 also signal pro-inflammatory pathways [21]

TNF increases the phagocytic capacity of macrophages and enhances the killing of intracellularly viable bacteria via the generation of reactive nitrogen and oxygen intermediates, effectively synergising with interferon (IFN)- $\gamma$ [22]. Neutralisation of TNF activity leads to resumption of mycobacterial growth within granulomas during chronic latent infection $[23,24]$. Mice deficient in TNF or TNFR p55 have dramatically increased microbial loads and succumb prematurely to disease

TABLE 1 Description of levels of evidence

Evidence Sources of evidence Definition

category

A Randomised controlled trials Rich body of data

B

Randomised controlled trials Limited body of data

C

D
Nonrandomised trials Observational studies Panel consensus judgement
Evidence is from end-points of well-designed randomised controlled trials that provide a consistent pattern of findings in the population for which the recommendation is made. Category A requires substantial numbers of studies involving substantial numbers of participants.

Evidence is from end-points of intervention studies that include only a limited number of patients, post hoc or subgroup analysis of randomised controlled trials, or meta-analysis of randomised controlled trials. In general, category B pertains when few randomised trials exist, they are small in size, they were undertaken in a population that differs from the target population of the recommendation, or the results are somewhat inconsistent.

Evidence is from outcomes of uncontrolled or nonrandomised trials or from observational studies.

This category is used only in cases where the provision of some guidance was deemed valuable but the clinical literature addressing the subject was deemed insufficient to justify placement in one of the other categories. The panel consensus is based on clinical experience or knowledge that does not meet the above-listed criteria. 
caused by Listeria monocytogenes, M. tuberculosis or Histoplasmosis capsulatum [25-27].

TNF stimulates the production of chemokines such as CCL2, CCL3, CCL4, CCL5 and CCL8 in macrophages and T-cells and induces the expression of vascular adhesion molecules such as CD54, promoting a focused accumulation of immune cells at the site of infection $[27,28]$. In this way, TNF is responsible for granuloma initiation and maintenance of granuloma integrity. In TNF-deficient mice infected with $M$. tuberculosis, granuloma formation is delayed and malorganised, leading to inefficient containment of infectious foci [29]. Similarly, neutralisation of TNF activity following the establishment of granulomas results in their structural disintegration [23, 24]. tmTNF alone is sufficient for mounting early resistance against mycobacterial infections by regulating T-helper (Th)1-type cytokine and chemokine expression but, in the absence of STNF, is insufficient to provide lasting anti-mycobacterial protection (fig. 1) [30, 31].

TNF has long been postulated to be directly involved in caseation necrosis, because infection of cells with $M$. tuberculosis renders them highly sensitive to killing by TNF in vitro [32]. Moreover, treatment of $M$. tuberculosis-infected mice with recombinant TNF resulted in increased inflammation in the lungs and accelerated mortality [33]. However, TNF also plays a regulatory role during mycobacteria-induced inflammation. For example, TNF can induce apoptosis in TNF receptor p55 bearing cells thereby eliminating excessive cellular responses [24]. TNF can also act as a survival factor and may be involved in the maintenance of macrophage viability at the site of infection. In TNFR p55-knockout mice infected with Mycobacterium avium, the granuloma structure cannot be maintained, and the dysregulated, hyperinflammatory response causes premature death of infected mice [34]. TNF (and also IFN- $\gamma$ ), possibly via the induction of inducible nitric oxide synthase, therefore also serves to downregulate an exacerbated inflammatory response, in part by inducing apoptosis of effector T-cells [35].

Thus TNF plays a critical role in the host response to infection. The closely related cytokines, lymphotoxins (LT) $\alpha$ and $\beta$, which occur as homo- or heterotrimers, also contribute to antimycobacterial and granulomagenic activities, but are insufficient alone to support granuloma formation in the absence of TNF [36-38]. On the other hand, $\mathrm{LT}_{3}$ is necessary for establishing the proper architecture of the granuloma, since, in the absence of $\mathrm{LT}_{3}, \mathrm{~T}$-cells do not migrate into the granulomatous lesion but only accumulate in perivascular cuffs (fig. 1) [24].

\section{TNF antagonists}

Four monoclonal anti-TNF antibodies are currently in clinical use: infliximab, adalimumab, golimumab and certolizumab pegol (fig. 2) [21, 39]. Infliximab is comprised of human immunoglobulin (Ig)G1 constant regions and murine variable regions, whereas adalimumab and golimumab both have human IgG1 constant and variable regions. Certolizumab pegol is a pegylated, humanised Fab' fragment. Infliximab, adalimumab and golimumab are approved for treatment of rheumatoid arthritis, psoriatic arthritis and ankylosing spondylitis. Infliximab, adalimumab and certolizumab are approved for treatment of Crohn's disease. Infliximab is also

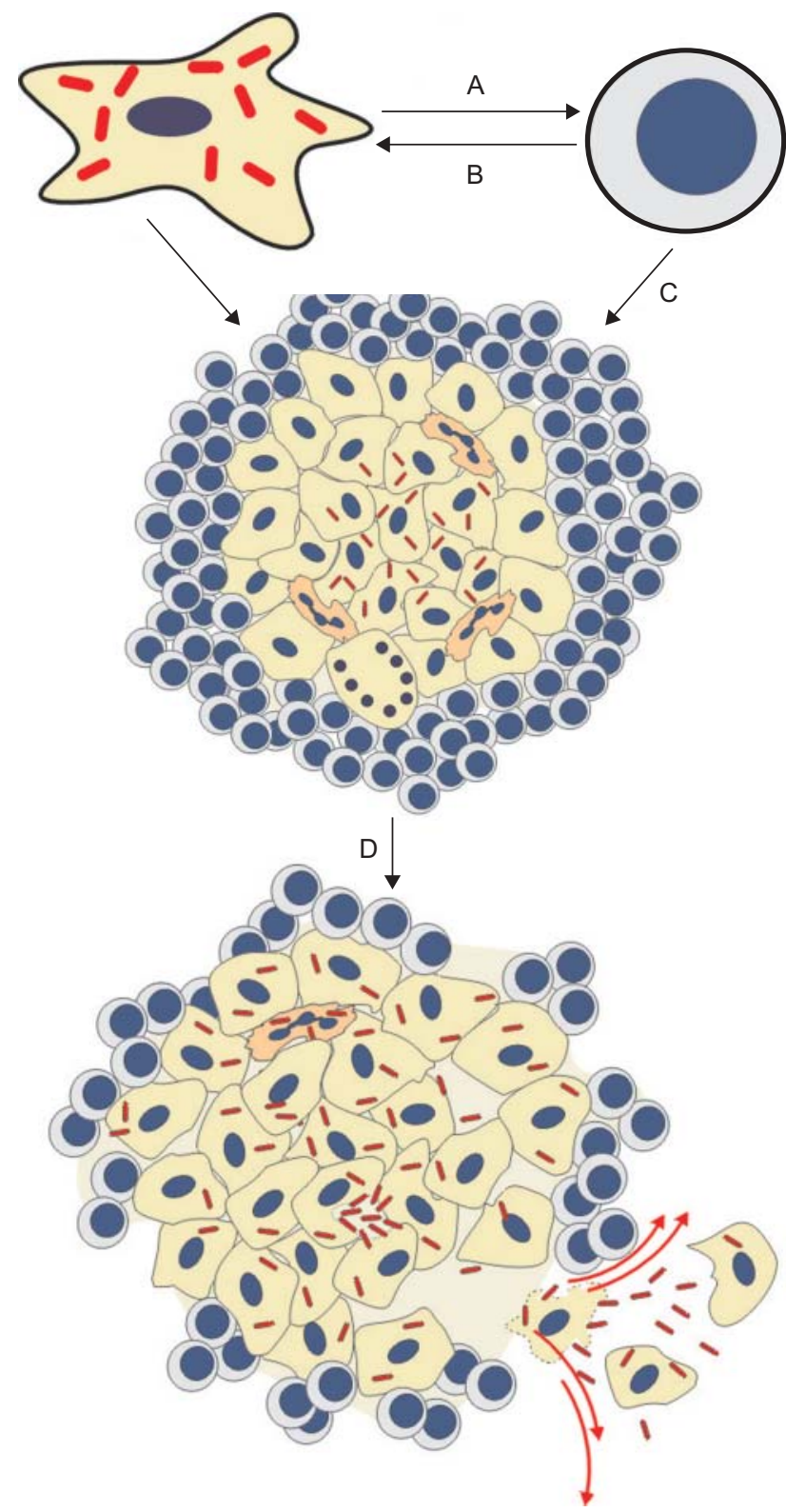

FIGURE 1. Tumour necrosis factor (TNF) acts at multiple steps in antibacterial and inflammatory responses to Mycobacterium tuberculosis infection. A: macrophage-derived TNF acts as a co-stimulus for T-cells. B: T-cell-derived TNF primes macrophages for mycobactericidal activity. C: macrophage- and T-cellderived TNF (together with interferon (IFN)- $\gamma$ and chemokines) induce recruitment and organised accumulation of mononuclear cells into highly structured granulomas TNF and IFN- $\gamma$ also regulate excessive inflammation by inducing apoptosis of T-cells. D: TNF antagonist therapy results in granuloma breakdown and dissemination of mycobacteria. Reproduced from [10] with permission from the publisher.

approved for ulcerative colitis, and may be effective in sarcoidosis. Certolizumab also appears to be effective for rheumatoid arthritis. Infliximab is administered by intravenous infusion, producing peak blood concentrations of $80 \mu \mathrm{g} \cdot \mathrm{mL}^{-1}$. Adalimumab, certolizumab and golimumab are administered by subcutaneous injection. Peak blood concentrations of $10 \mu \mathrm{g} \cdot \mathrm{mL}^{-1}$ have been reported for adalimumab, $90 \mu \mathrm{g} \cdot \mathrm{mL}^{-1}$ for certolizumab and $2.5 \mu \mathrm{g} \cdot \mathrm{mL}^{-1}$ for golimumab. 


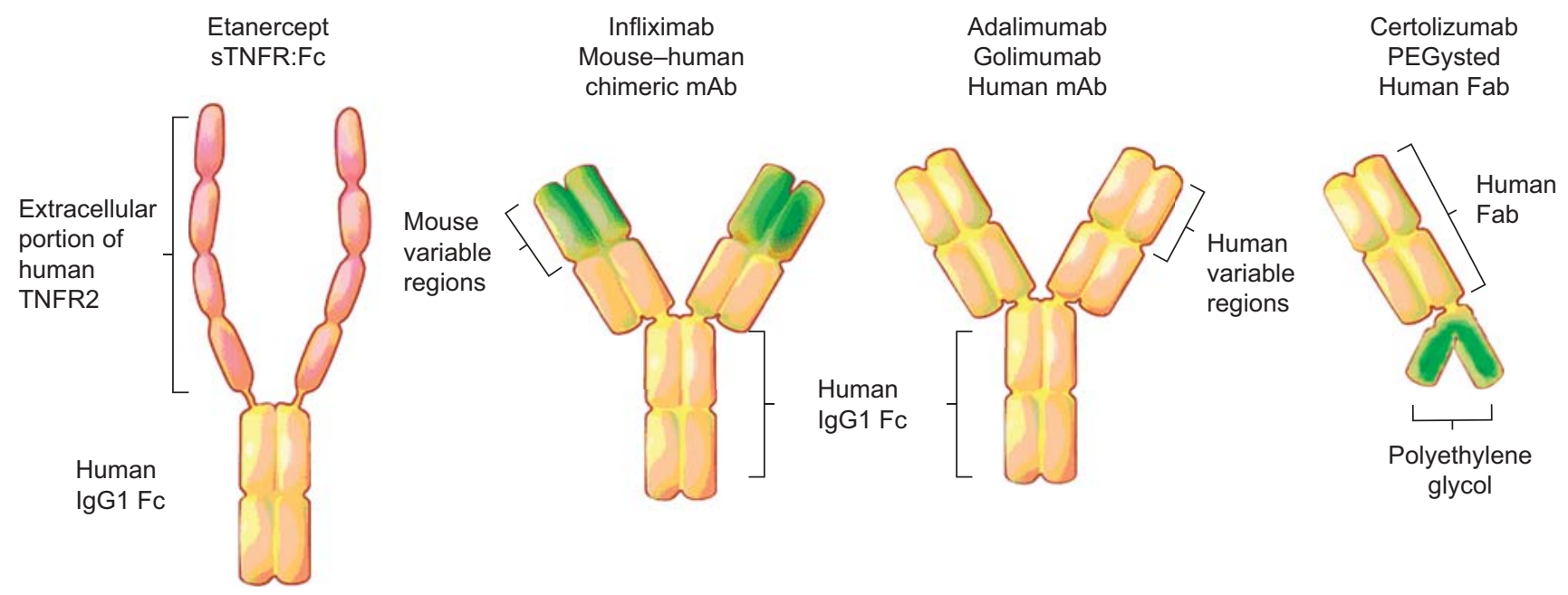

FIGURE 2. Structures of the tumour necrosis factor (TNF) antagonists. TNFR: TNF receptor; sTNFR: soluble TNFR; Ig; immunoglobulin; mAb: monoclonal antibody Adapted from [39] with permission from the publisher.

Etanercept is the only soluble TNF receptor currently in clinical use. It is comprised of two extracellular domains of human TNF-R2 fused to the FC fragment of human IgG1. It binds trimeric TNF and lymphotoxin. Etanercept is approved for the treatment of rheumatoid arthritis, psoriatic arthritis, psoriasis, juvenile rheumatoid arthritis and ankylosing spondylitis. Etanercept is not effective against granulomatous inflammatory conditions such as Crohn's disease or sarcoidosis. It is administered by subcutaneous injection, usually once or twice weekly, producing blood concentrations of $1-2.4 \mu \mathrm{g} \cdot \mathrm{mL}^{-1}$.

\section{Structure-function relationship: clues for better TNF antagonist therapies}

It is biologically plausible that efficacy against chronic granulomatous inflammation and efficiency in reactivating latent M. tuberculosis infection are linked. Structural and functional differences among the TNF antagonists may account for their differences in these properties [39]. Peak blood levels of infliximab are several times those of other TNF antagonists; however, this does not appear to confer any unique clinical characteristics. TNF readily dissociates from etanercept which releases $>90 \%$ of bound cytokine within $2-3 \mathrm{~h}$; dissociation of TNF from infliximab was undetectable in the same study [40]. However, in a study using plasmon resonance to examine binding affinities of TNF antagonists for sTNF, adalimumab and infliximab were found to be less potent than etanercept and certolizumab. Etanercept binds less strongly to tmTNF than infliximab, so that neutralisation of tmTNF signalling is two-fold greater for certolizumab, infliximab and adalimumab compared with etanercept [40]. Anti-TNF monoclonal antibodies were reported to inhibit T-cell activation and cytokine (including IFN- $\gamma$ ) expression, while etanercept showed reduced or no effects in this regard [41-43].

Several studies have examined the ability of anti-TNF antibodies to cross-link transmembrane TNF and thereby induce apoptosis in TNF-expressing T-cells. This activity can be demonstrated in vitro using reporter cell constructs, and in vivo in cells infiltrating the gut of Crohn's disease patients [4448]. Etanercept lacks this activity. Defective apoptosis in gut lymphocytes is thought to be central to the pathogenesis of Crohn's disease. Other studies have examined complementmediated lysis of TNF-expressing T-cells. For example, BRUNS et al. [49] found that numbers of circulating effector memory CD8 T-cells were reduced by infliximab treatment.

However, experience with the Fab' TNF antibody fragment certolizumab pegol calls into question the significance of many of these observations. With only one TNF binding region and without $\mathrm{Fc}$, certolizumab can neither crosslink tmTNF nor activate complement and, therefore, can induce neither apoptosis nor necrosis in TNF-expressing cells. Nonetheless, certolizumab is highly effective as therapy for Crohn's disease [50], and appears to efficiently reactivate TB (see below). These findings suggest that other properties, such as binding avidity and inhibition of cell activation must, therefore, be more important than induction of cell death. This is consistent with computer simulations indicating that even low levels of sTNF were sufficient for control of latent infection with $M$. tuberculosis [51].

These arguments notwithstanding, there are convincing experimental data that selective inhibition of sTNF only, while sparing tmTNF activity, may be beneficial. For example, a selective inhibitor of STNF efficiently protected mice from acute liver inflammation yet maintained immunity to mycobacterial infections. In contrast, nonselective inhibition of both sTNF and tmTNF suppressed immunity to M. bovis BCG and M. tuberculosis $[52,53]$.

\section{Summary}

In summary, TNF is critical for macrophage activation and immune cell recruitment to the granuloma. In its absence, granulomas disintegrate and facilitate mycobacterial re-growth and dissemination. The efficacy of different TNF antagonists against granulomatous disorders correlates with their activity in reactivating $\mathrm{TB}$. This is probably due to both different pharmacokinetics and different modes of action. Differential induction of apoptosis (particularly in T-cells) and differential inhibition of soluble versus transmembrane TNF may account for some of the observed differences in reactivating $\mathrm{TB}$ 
following treatment with anti-TNF antibodies versus soluble TNF receptor constructs.

\section{TNF ANTAGONIST THERAPY IN RHEUMATOID} ARTHRITIS: HISTORY, CLINICAL EFFECT AND DOSING

TNF was found to be one of the key cytokines in the pathogenesis of rheumatoid arthritis and other inflammatory rheumatic diseases. This finding has led to the development of drug-targeted therapies for the first time in inflammatory rheumatic conditions [54]. Today, all the available TNF antagonists are licensed for the treatment of rheumatoid arthritis while their approval status for other rheumatic diseases differs (table 2).

\section{Rheumatoid arthritis}

Rheumatoid arthritis is the most common inflammatory rheumatic disease characterised by chronic synovial inflammation and progressive erosive polyarticular joint damage. Data from the first randomised controlled clinical trial on a TNF antagonist were reported in 1994 and showed significant improvement of signs and symptoms after treatment with infliximab compared with placebo [55]. Thereafter, numerous clinical trials demonstrated that infliximab, etanercept, adalimumab, golimumab and certolizumab improved not only signs and symptoms, and health-related quality of life but also delay the progression of joint damage [56]. TNF antagonists administered as single agents are not significantly superior to methotrexate in controlling signs and symptoms, but exhibit significant improvement compared with traditional disease modifying antirheumatic drugs (DMARD) when given together with methotrexate in DMARD-incomplete responder patients. Therefore, treatment with TNF- $\alpha$ antagonists in established rheumatoid arthritis is recommended in most guidelines for patients who partially respond to at least one conventional DMARD including methotrexate (table 2) [56, 57]. Infliximab is licensed only in combination with methotrexate. A clinically significant improvement with TNF antagonists in combination with methotrexate is seen in around two-thirds of the patients. Furthermore, clinical disease remission (i.e. DAS28 score <2.6) can be achieved in up to $30 \%$ of DMARD-incomplete responder patients and close to $50 \%$ of DMARD-naïve early rheumatoid arthritis patients [58].

Based on published evidence [59], the American College of Rheumatology recently recommended the use of a TNF antagonist in combination with methotrexate in DMARDnaïve early rheumatoid arthritis (disease duration $<3$ months) patients with high disease activity and markers of poor prognosis, in the absence of treatment cost-related limitations [57]. In contrast, the European League against Rheumatism recommends initial therapy with methotrexate in early rheumatoid arthritis because of a favourable benefit/to risk ratio and its cost-effectiveness [60].

Randomised clinical trials comparing the efficacy of the different TNF blocking agents have not yet been reported. However, none of the meta-analyses, including reported clinical trials, have provided evidence that one TNF antagonist is significantly superior over the other in terms of clinically relevant outcomes [56].

\section{Ankylosing spondylitis}

Efficacy of infliximab for treatment of ankylosing spondylitis was confirmed in a randomised clinical trial for the first time in 2002 [61]. Thereafter, several clinical trials have demonstrated that infliximab, adalimumab and etanercept provide significant and sustained improvement in clinical scores, such as the Bath Ankylosing Spondylitis Disease Activity Index and the Bath Ankylosing Spondylitis Functional Index, and in uveitis $[62,63]$. In contrast to rheumatoid arthritis and psoriatic arthritis, the impact on joint damage is debated $[64,65]$. Indirect comparisons of clinical trials did not demonstrate superiority of one TNF antagonist over the other in the improvement of signs and symptoms (table 2) [63].

\section{Psoriatic arthritis}

In psoriatic arthritis, infliximab, etanercept, adalimumab and golimumab are all efficacious in the treatment of both joint and skin disease [66]. Radiographic data show that etanercept and infliximab can also delay progression of joint damage (table 2) [66].

\section{Juvenile idiopathic arthritis}

At present, etanercept and adalimumab are approved for treatment of juvenile idiopathic arthritis incomplete DMARD responder patients (table 2). A significant and sustained reduction in disease activity is seen in $\sim 60 \%$ of patients in articular manifestations and uveitis [67, 68]. However, only $25 \%$ of patients attain remission, and disease flares occur in $\sim 50 \%$ once in remission [69].

\section{Summary}

In summary, in rheumatoid arthritis TNF antagonists not only improve signs and symptoms and health-related quality of life, but also delay the progression of joint damage. In ankylosing spondylitis, TNF antagonists are efficacious for treatment of axial involvement and extraarticular manifestations. In rheumatic diseases, there is as yet no evidence that one TNF antagonist is significantly superior over the other.

\section{TNF ANTAGONIST THERAPY IN INFLAMMATORY BOWEL DISEASE: HISTORY, CLINICAL EFFECT AND DOSING}

Presently, three different TNF antagonists are approved for the therapy of inflammatory bowel disease. These are infliximab (for both Crohn's disease and ulcerative colitis) [70-72], adalimumab (Crohn's disease) [73], and certolizumab pegol (Crohn's disease, not approved in the European Union) (table 2) [74, 75]. Apart from infliximab, adalimumab and certolizumab several further TNF antagonists are in development with golimumab being the one that is most advanced in development and presently undergoing phase III clinical trials in ulcerative colitis.

Clinical efficacy is similar between the different TNF antagonists that induce response in $\sim 60 \%$ of patients with complicated Crohn's disease (table 2). This has first been established for infliximab through a landmark trial in which efficacy could be demonstrated in patients with Crohn's disease [70]. Of the responders $\sim 40-50 \%$ could be maintained over a long time; several years of maintenance efficacy during open label followup have been documented for some of the agents. Interestingly, use of TNF antagonists early in the course of 
TABLE 2 Tumour necrosis factor antagonists: licensed indications, conditions for prescription and dosing

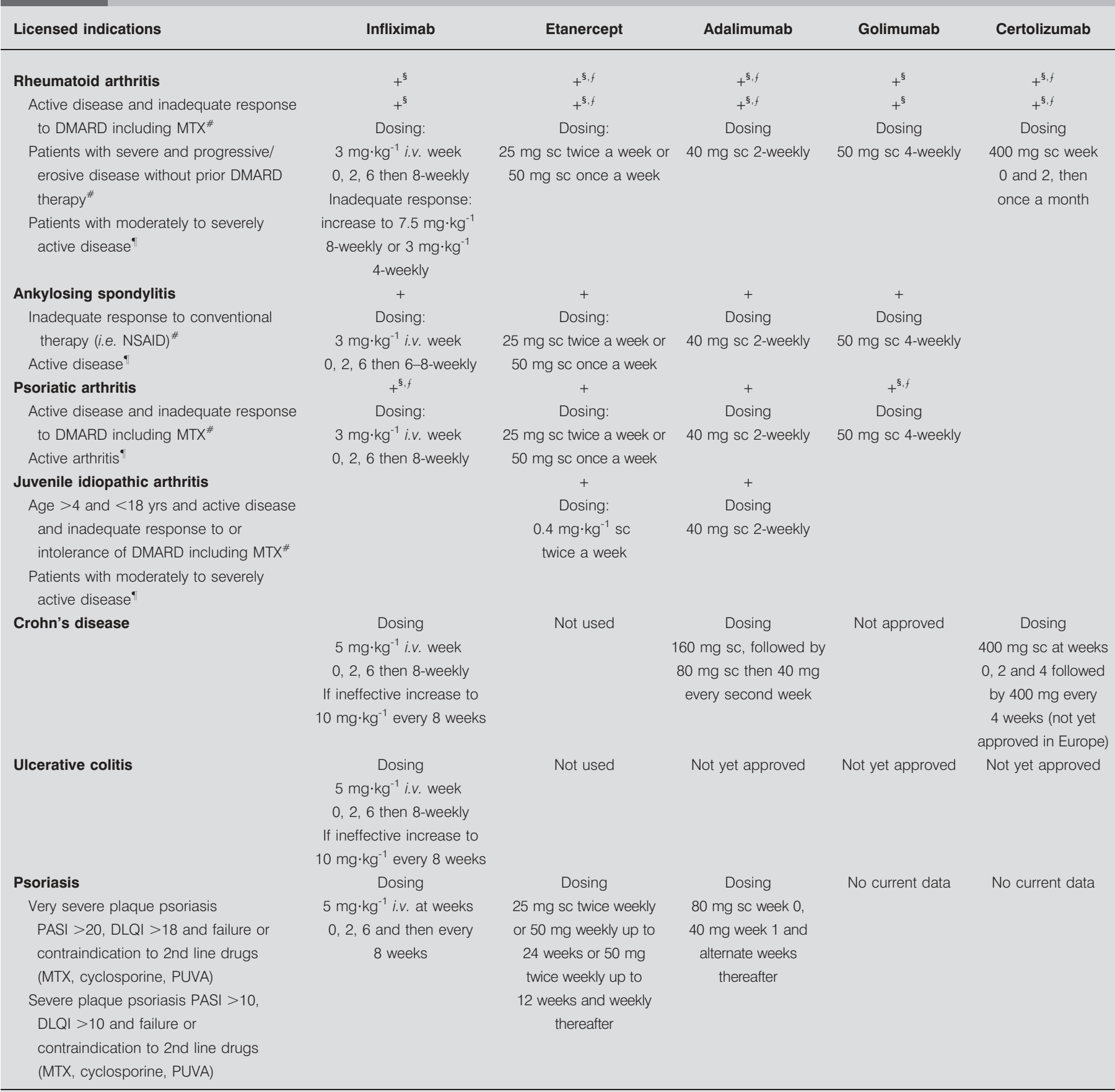

DMARD: disease-modifying anti-rheumatic drug; MTX: methotrexate; NSAID: nonsteroidal anti-rheumatic drug; PASI: Psoriasis Area Severity Index; DLQI: Dermatology

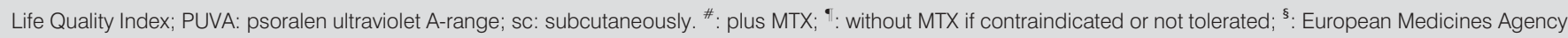
approved indication; f: Federal Drug Administration approved indication.

disease (i.e. before patients have received oral immunosuppressants such as azathioprine which corresponds to a median disease duration of $\sim 2.4$ yrs) leads to a much higher level of efficacy [76], with almost $70 \%$ of Crohn's disease patients achieving corticosteroid-free remission as an end-point after $1 \mathrm{yr}$ of therapy. This end-point "corticosteroid-free remission" historically was first defined for TNF antagonist therapy, as former therapeutic options (standard therapy) were not capable of inducing corticosteroid-free remission in a larger percentage of patients. Treatment with TNF antagonists is the first therapy that leads to ulcer healing and closes other overt lesions in the inflamed mucosa as evidenced by endoscopy. This is seen as early as 10 weeks after the start of therapy. For the first time a correlation between Crohn's disease activity 
index and Crohn's disease endoscopic index of severity has been observed under TNF antagonist therapies.

All TNF antagonising drugs close perianal and other fistulae. Again, this is a new therapeutic quality that was not achieved with the standard therapies available in the pre-TNF antagonist era. Maintenance of closure (which is successful in $~ 50 \%$ of cases over a 1-yr duration) requires continued TNF antagonist therapy.

Long-term problems in inflammatory bowel disease comprise structural damage (e.g. stenoses or fistulae) that lead to longterm morbidity and frequent hospitalisation and surgery. TNF antagonist therapy reduces the rate of disease-related hospitalisation and surgery. Infliximab is also approved for use in paediatric Crohn's disease.

Adverse drug-events due to TNF antagonist therapies are similar between the agents. Some differentiation in such events seen in inflammatory bowel disease from other disorders occurs as a result of the young age of patients with inflammatory bowel disease in comparison with other indications. Therefore, some problems are less frequently seen in inflammatory bowel disease (e.g. reactivation of $\mathrm{TB})$ whereas others are unique $(e . g$. hepatosplenic lymphoma, a rare complication that occurs when infliximab is given in combination with azathioprine in young males). Crohn's disease appears to be a condition in which immunogenicity of foreign proteins may play a particular role. Overlooked abscesses, in particular in patients with fistula systems, are an important source of infectious complications. In past years it has become apparent that many of the adverse drug events associated with TNF antagonist therapy can be attributed to the co-medication (azathioprine and glucocorticoids) or to poorly managed chronic active disease.

\section{Summary}

In summary, three different TNF antagonists with clinical efficacy (infliximab, adalimumab and certolizumab pegol) for remission induction and maintenance of remission are available and a fourth agent (golimumab) is in advanced clinical development. Efficacy end-points include mucosal healing, glucocorticoid free remission and fistula closure. Doses needed for inflammatory bowel disease are, in general, higher than for rheumatoid arthritis. Infliximab is the only agent approved for ulcerative colitis and for paediatric Crohn's disease.

\section{TNF ANTAGONIST THERAPY IN PSORIASIS: HISTORY, CLINICAL EFFECT AND DOSING}

TNF is a product of various skin cell types and has been shown to be pro-inflammatory when released into the skin [77]. Its central importance in inflammatory skin disease has been demonstrated by the high level of effectiveness of TNF antagonists in psoriasis [78]. Although psoriasis is the most important dermatological indication for TNF antagonists (table 2), these drugs are now developing indications in other inflammatory dermatological conditions.

\section{Psoriasis}

Infliximab was first reported to be of utility in psoriasis in 2000 [79]. This was a serendipitous observation of clearing of psoriasis in a patient with co-existing Crohn's disease undergoing TNF antagonist treatment. Since then there have been numerous reports confirming the effectiveness of all TNF antagonists (infliximab, etanercept and adalimumab) in various forms of the disease.

Infliximab has been used in the treatment of psoriasis at doses of $3-10 \mathrm{mg} \cdot \mathrm{kg}^{-1}$ and is now generally used at a dose of $5 \mathrm{mg} \cdot \mathrm{kg}^{-1}$ with an induction regimen consisting of dosing at 0,2 and 6 weeks followed by regular 8-weekly infusions. Secondary treatment failure appears to be minimised by regular rather than intermittent dosing [80]. There is also an increasing trend towards concomitant use of low dose methotrexate in patients on infliximab [81] in order to reduce the risk of secondary failure, although firm evidence of this is lacking [78]. Secondary failure with infliximab is unpredictable, although it seems to be associated with the development of antinuclear antibodies [82]. Infliximab is highly effective, resulting in $75 \%$ clearance of psoriasis (Psoriasis Area and Severity Index (PASI) 75) in $>70 \%$ patients at 12 weeks [83]. In addition to improving the chronic plaque form of the disease, infliximab has been shown to be of utility in generalised pustular psoriasis in small case series [84], although palmar plantar pustular psoriasis does not appear to respond and may even be precipitated by TNF antagonist therapy [85]. Improvement of nail disease has been demonstrated [86].

Etanercept appears less effective than infliximab, although it is more convenient for patients as it can be administered at home. Doses of $25-50 \mathrm{mg}$ twice weekly are employed with typical PASI75 responses of $34-48 \%$ at 12 weeks [87]. Longer dosing periods result in increases in PASI75 response to $43-57 \%$. Etanercept has been shown to be effective in the treatment of psoriasis in children [88] and is licensed for use in children in the UK at a dose of up to $0.8 \mathrm{mg} \cdot \mathrm{kg}^{-1}$ to a maximum of $50 \mathrm{mg}$ weekly.

Adalimumab appears to combine advantages of infliximab and etanercept in that it seems to have a similar efficacy to infliximab, yet can be administered at home by the patient [89, 90]. It is generally used with an induction regimen of $80 \mathrm{mg}$ at week 0 , followed by $40 \mathrm{mg}$ and 12-week PASI75 responses of $69-80 \%$ have been reported.

There are currently few data to guide sequencing of TNF antagonist therapies in patients who either fail to respond to treatment at all (primary failure) or who respond initially and then lose efficacy (secondary failure), although failure of response to one drug does not appear to predict failure of response to another [91, 92].

Adverse effects of TNF antagonists in the treatment of dermatological disease are much the same as those experienced in other indications reviewed elsewhere in this article. Mention should however be made of the rare paradoxical appearance of psoriasis-like skin lesions in patients with rheumatological and gastrointestinal disease treated with TNF antagonists [93, 94]. The mechanisms underlying these reactions, which tend to resolve following withdrawal of treatment, are unclear. They do however suggest that psoriasis is not one disease but potentially the result of several different pathogenetic pathways.

\section{Dermatological indications other than psoriasis}

Whilst TNF antagonists have been used successfully off-label in a number of other dermatological conditions including 
hidradenitis suppurativa [95], sarcoidosis [96] and pyoderma gangrenosum [97], robust data on their effectiveness is awaited and will depend on properly controlled clinical studies. It seems clear, however, that with time, the indications for these drugs in dermatology will expand.

\section{Summary}

In summary, infliximab, adalimumab and etanercept are licensed for the treatment of moderate to severe psoriasis. Infliximab and adalimumab are highly effective, resulting in positive treatment responses in $>70 \%$ of patients with psoriasis. Secondary treatment failure appears to be minimised by regular rather than intermittent dosing.

\section{THE RISK OF TB FOLLOWING TNF ANTAGONIST THERAPIES}

In Canada, Europe and Asia, the relative risk of TB in rheumatoid arthritis ranges between 2 and 16 owing to the disease itself and the use of non-biological medications [4, 98101]. In contrast, in one study from the US using nonstandardised rates for comparison, no increased risk was found [11]. In rheumatic diseases other than rheumatoid arthritis this information is missing.

TNF is crucial in host immunity to M. tuberculosis and other intracellular bacteria [102]. In murine models, TNF deficiency increases susceptibility to primary infection with $\mathrm{M}$. tuberculosis [29] and experimental depletion of TNF causes active TB in mice that previously controlled M. tuberculosis infection [36, $103,104]$. In humans, therapy with TNF antagonists results in reduction of granulysin-expressing $\mathrm{CD}^{+} \mathrm{CCR} 7^{-} \mathrm{CD} 45 \mathrm{RA}^{+}$ effector memory T-cells, disrupting a component of protective immunity against intracellular bacteria [49]. Clinical studies of the impact of TNF antagonists on TB face several challenges, as TB rates vary substantially by country and ethnicity, and may be influenced by underlying medical conditions (table 3). Three strategies for data collection have been used. A study published in 2004 identified 138 TB cases in patients treated with TNF antagonists that had been voluntarily reported to the US Food and Drug Administration through its adverse event reporting system [12]. The TB risk posed by infliximab appeared to be twice that of etanercept. Risks of histoplasmosis and coccidioidomycosis were also increased six to seven-fold.
A study published in 2006 identified 51 TB cases in Canadian rheumatoid arthritis patients treated with TNF antagonists through a search of a large pharmacy prescription database [105]. The risk posed by infliximab was 1.3 times that of etanercept. However, the authors used prescriptions for isoniazid as an indicator for TB and, therefore, probably misclassified latent infection with $M$. tuberculosis as TB [108, 109]. Another study from the BIOBADASER (Spanish Registry of Adverse Events of Biological Therapies in Rheumatic Diseases) registry reported a not significantly different risk of active TB posed by all three TNF antagonits; a trend toward a two-fold increased rate was noted for infliximab, but the study was limited in its statistical power [14]. A recent study identified 69 TB cases prospectively through the French RATIO registry [106]. The sex and age-adjusted TB incidence rate was 1.17 per 1,000 patient-yrs, 12.2 times that of the general population. Nearly all of the excess risk was due to infliximab (standardised incidence ratio (SIR) 18.6, 95\% CI 13.4-25.8) and adalimumab (SIR 29.3, 95\% CI 20.2-42.4) rather than etanercept (SIR 1.8, 95\% CI 0.7-4.3). A similar conclusion was reached by a Portuguese biologics registry study of $13 \mathrm{~TB}$ cases that found the TB risk with anti-TNF antibodies to be 12fold greater than with etanercept [110]. In the most recent study by the British Society for Rheumatology Biologics Register, the rate of TB in patients with rheumatoid arthritis treated with TNF antagonist therapies was three to four-fold higher in patients receiving infliximab and adalimumab than in those receiving etanercept [110]. These studies indicate that the antibodies adalimumab and infliximab share a higher risk of progression to TB than soluble TNF receptor, correlating with therapeutic efficacy against chronic granulomatous inflammation in Crohn's disease. It does not correlate with the risk of other mycobacterioses, which appears to be similar for both drug classes [12, 112].

Most of the active TB cases in patients treated with TNF antagonists are due to reactivation of latent infection with $M$. tuberculosis. TB in patients who have been treated with TNF antagonist therapies usually progresses rapidly and is frequently disseminated. The most effective way to avoid reactivation is the treatment of the latent infection. A number of countries have generated national guidelines to deal with

TABLE 3 Risk of active tuberculosis in different studies in patients suffering from rheumatic diseases treated with TNF antagonists

\begin{tabular}{|c|c|c|c|c|c|c|}
\hline First author [ref.] & Country & Type of study & Adalimumab & Etanercept & Infliximab & Comments \\
\hline WALLIS [12] & USA & $\begin{array}{c}\text { Cases voluntarily reported } \\
\text { to US FDA }\end{array}$ & & IR 28/100000 & IR 54/100000 & $\begin{array}{l}\text { Etanercept versus infliximab } \\
\qquad p<0.0001\end{array}$ \\
\hline BRASSARD [105] & Canada & $\begin{array}{l}\text { Search of a large pharmacy } \\
\text { prescription database }\end{array}$ & & RR $1.2(0.9-1.8)$ & RR 1.6 (1.0-2.6) & \\
\hline GomeZ-Reino [14] & Spain & Data from registry & IR 176/100000 & IR $114 / 100000$ & IR 383/100000 & $\mathrm{p}=\mathrm{NS}$, wide confidence interval \\
\hline FonSECA [107] & Portugal & Data from registry & 4 cases/171 patients & 1 case/333 patients & 8 cases/456 patients & Exposure is not provided \\
\hline
\end{tabular}

US FDA: US Food and Drug Administration; IR: incidence rate; RR: adjusted rate ratio; NS: nonsignificant; SIR: standardised incidence ratio. 
latent infection with $M$. tuberculosis before treatment with TNF antagonists [20, 113-118], with significant differences regarding the use and interpretation of the tuberculin skin test, IGRA and the indications for preventive treatment. The diagnosis of latent infection with $M$. tuberculosis is traditionally based on tuberculin skin test positivity in the absence of manifest TB. The skin test has a low sensitivity in patients with rheumatoid arthritis [119], and may be falsely positive in patients with prior BCG vaccination or prior sensitisation resulting from infection with environmental mycobacteria. Therefore, skin test results must be interpreted taking the pre-test risk of infection attributable to $M$. tuberculosis and the risk of reactivation into consideration. A positive tuberculin skin test in populations in whom TB is or has been highly incident should be considered as positive, regardless of a history of prior BCG vaccination. Conversely, it may be difficult to exclude latent infection with $M$. tuberculosis in regions where TB has a low incidence but the prevalence of prior BCG vaccination is high. IGRAs are proposed as an alternative for the tuberculin skin test [120]. The positive predictive value of an IGRA for the development of TB is most probably better than that for a positive skin test, but the negative predictive value is unclear.

Definitive recommendations to use IGRAs as the only diagnostic method to test for latent TB infection cannot be made before more clinical data on their role in predicting TB become available.

Some patients have developed TB after receiving infliximab despite a negative initial skin test result [121]. Despite negative results of immunodiagnostic tests, physicians should carefully question candidates for TNF antagonists therapies about prior exposure to TB. Chest radiographs may be helpful to identify radiographic evidence of prior $\mathrm{TB}$ or signs of current $\mathrm{TB}$ among such patients. Thus, when indicated, appropriate bacteriological examinations, and if M. tuberculosis is isolated, drug susceptibility testing by rapid methods (either liquid culture or molecular testing) are essential diagnostic procedures to prevent disease progression and dissemination. Standard four-drug therapy for TB should be started soon in all cases of suspected or documented active TB.

\section{Summary}

In summary, the risk of active TB is increased in rheumatoid arthritis. Treatment with TNF antagonists further increases the risk over the background in this and other chronic inflammatory arthropathies. Reactivation of latent infection with $M$. tuberculosis is the pathogenetic pathway in the majority of active TB cases in chronic inflammatory arthropathies. Tuberculin skin testing and preventive therapy is successful in programmes to prevent reactivation of $\mathrm{TB}$ in patients with chronic inflammatory rheumatic conditions (evidence level C). Similar evidence concerning IGRA is lacking.

\section{IMMUNODIAGNOSTICS TO IDENTIFY INDIVIDUALS AT} RISK OF DEVELOPING TB ON IMMUNOBIOLOGICALS

Infection with $M$. tuberculosis induces a strong Th1-type cellular immune response $[8,122,123]$. As it is currently impossible to directly identify tubercle bacilli from persons latently infected with $M$. tuberculosis, the presence of a cellular immune response serves as the only diagnostic measure to assess prior contact and future risk of developing TB [122, 124]. Two test principles are currently available to detect specific immunity. The tuberculin skin test has been in use for more than a century [125] and elicits a delayed-type hypersensitivity response after local intradermal application of purified protein derivative (PPD), an extract of the sterile supernatant of $M$. tuberculosis culture filtrate. The largest diameter in millimetres of the tuberculin skin test induration transverse to the long axis of the arm is measured $48-72 \mathrm{~h}$ after antigen injection. Reliability of the measurement might be improved by using the "ballpoint technique" [126]. More recently, in vitro tests to detect specific cell-mediated immune responses towards $M$. tuberculosis have been developed and implemented for clinical routine that share many basic principles of skin testing, yet have a number of operational advantages and a superior diagnostic accuracy. When performing in vitro tests, peripheral blood cells are stimulated with specific antigens. Effector Tcells recognising these antigens are rapidly activated and secrete a variety of cytokines within hours after stimulation. As the cytokine IFN- $\gamma$ is a good marker for specific activation of Tcells, and has been widely used to detect $M$. tuberculosisspecific responses, these assays have been termed IGRAs [127]. The percentage of blood cells releasing IFN- $\gamma$ may be determined using an enzyme-linked immunospot (ELISPOT) assay [128, 129] or the amount of IFN- $\gamma$ released into the supernatant may be quantified using an ELISA [130]. Commercial tests are available for both formats (ELISPOT as T-SPOT.TB; Oxford Immunotec, Oxford, UK, and ELISA as QuantiFERON TB Gold in-tube; Cellestis Ltd, Carnegie, Australia). Alternatively, IFN- $\gamma$ may be accumulated intracellularly and detected using flow-cytometry [131-134]. An increase in specificity of IGRA over tuberculin skin testing has resulted from the identification of genomic segments (regions of difference (RD) 1 or 11) within M. tuberculosis that are absent in all strains of BCG and most environmental mycobacteria including the M. avium complex [127, 135, 136]. Among those, early secretory antigenic target-6, culture filtrate protein-10, both RD1-derived, or TB7.7 (RD11-derived) are used in the commercially available assays and most in-house assays, as they elicit strong Th1 type immune responses. Hence, when used as stimuli, a specific T-cell response towards those antigens is a more specific marker for $M$. tuberculosis infection than a positive tuberculin skin test [129, 137], thereby reducing the frequency of false-positive skin test results in BCG-vaccinated individuals. In vitro assays have also been studied as an approach to increase sensitivity as compared to skin testing. This is of particular relevance in immunocompromised patients on immunosuppressive drug therapy, where skin testing has the inherent problem of potentially being falsely negative [134, 138]. Interestingly, the gain in sensitivity varies between studies and is dependent on the overall level of immunosuppression and on the in vitro assay that is applied, in that ELISPOT-based assays seem to be of higher sensitivity in immunocompromised patients compared to studies that used ELISA [16, 139]. As an operational advantage of in vitro assays that is of particular relevance in immunocompromised patients, specific stimulation reactions are not only accompanied by a negative control that allows assessment of nonspecific background reactivity, but also by a mitogen stimulus that is used as a positive control to assess general T-cell responsiveness. Although formally scored as 
"indeterminate result", a reduced mitogen response in patients on immunosuppressive drug therapy may be interpreted as a meaningful measure to assess the overall extent of immunosuppression. Therefore, unlike skin testing, in vitro tests may be able to discriminate true negative responses from anergy. Given the clear advantages over tuberculin skin testing, in vitro assays have been evaluated for their ability to assess evidence of prior infection with $M$. tuberculosis in both immunocompetent individuals as well as patients with immunodeficiencies, and are now licensed for clinical use in many countries [137, 140-142]. To date, however, no blood-based test allows distinction of active TB from latent infection or successfully treated disease.

As patients with immune-mediated inflammatory diseases are candidates for immunosuppressive and immunomodulatory medication that increase the risk for TB reactivation, and tuberculin skin test results in these patients are prone to be falsely negative, a number of cross-sectional and cohort studies have been performed to evaluate the use of IGRA as a clinically valuable alternative to skin testing. A summary of the main outcome of seminal studies that analysed the concordance of IGRA and tuberculin skin testing for screening of latent infection with $M$. tuberculosis in patients with immunemediated inflammatory diseases is given in table 4 [132, 143$149,150-154]$. In general, results of IGRAs and tuberculin skin tests correspond poorly, although agreement is stronger in countries with low TB prevalence and low BCG vaccination coverage [148]. In line with increased IGRA sensitivity and specificity in immunocompromised individuals, respectively, positive immune responses are more frequently observed with IGRAs than with the tuberculin skin test, especially in unvaccinated populations, and positive IGRA responses are more closely associated with risk factors for latent infection with M. tuberculosis. Moreover, the rate of indeterminate results was considerably low (0-10.3\%) (table 4). One important finding is that up to $50 \%$ of the IGRA positive patients are actually missed by the skin test. In the clinical setting, immunebased diagnosis for latent infection with M. tuberculosis is performed to identify individuals at risk of developing TB. However, to date, the positive predictive value of IGRA responses for the development of TB in candidates undergoing therapy with TNF antagonists is not known. A study conducted among individuals with HIV-infection from a low endemic area for TB indicates a very high negative predictive value of IGRAs in immunocompromised patients [155]. Currently it is unknown, whether individuals with a negative IGRA result and a medical history of TB or with imaging study findings suggestive of past TB or individuals with reverting IGRA results run a lower risk of TB than those with persistently positive IGRA results. Moreover, it is a subject of debate whether IGRA testing may also be superior to tuberculin skin testing for screening of patients who have already received TNF antagonists, as results vary from one study to another [42, 144, 148]. Therefore, recommendations that favour the use of IGRA over tuberculin skin testing to evaluate the risk for progression to $\mathrm{TB}$ in candidates for treatment with TNF antagonists are based on potential superiority in identifying latently infected individuals. While this is plausible, it cannot be taken as firm evidence until the positive predictive value of different immunodiagnostic tests have been compared in these patients.

\section{Summary}

In summary, the tuberculin skin testing measures cellmediated immunity towards PPD. Due to its poor specificity, the tuberculin skin test is inadequate to assess evidence of latent infection with $M$. tuberculosis in BCG-vaccinated patients and patients with low pre-test risk of TB infection. IGRAs are in vitro tests that rely on the rapid production of IFN- $\gamma$ by circulating mononuclear cells in response to antigens which are more specific for the detection of $M$. tuberculosis infection than PPD. IGRA testing in patients with immune-mediated inflammatory diseases is feasible due to a strong correlation with risk factors for $\mathrm{TB}$ and a low percentage of indeterminate results. Further longitudinal studies are needed to estimate the risk for progression to TB after IGRA-based and/or tuberculin skin test-based diagnosis of latent infection with $M$. tuberculosis in patients undergoing therapy with TNF antagonists.

\section{PREVENTIVE CHEMOTHERAPY}

Although adalimumab and infliximab share a higher risk for progression from latent infection to TB than soluble TNF receptor [12, 14, 105-107], preventive therapy is warranted in any case. The available evidence from a carefully assembled register-based observational study from Spain using a course of 9-months preventive therapy with isoniazid in persons judged from a tuberculin skin test result as likely to be infected with $M$. tuberculosis, suggests that the risk reduction might be as large as $80 \%$ if adherence to the regimen can be assured.

The indication for preventive therapy in general is ideally based on quantified information of the risk of TB imparted by a risk factor relative to a population that is similar in every respect except for the presence of that factor. Because TB will only develop among persons who are latently infected with $M$. tuberculosis, the referent population must have latent infection with $M$. tuberculosis. As this cannot be measured with current tools, the proxy for its measurement is a positive tuberculin skin test or positive IGRA test [124]. However, for a decision to recommend antimicrobial therapy to prevent TB, knowledge about the timing of tuberculin skin test or IGRA conversion is very helpful as the risk for the development of TB is low (incidence of about one per 1,000 person-yrs) when infection with $M$. tuberculosis occurred $>7$ yrs before in an otherwise healthy individual [156].

Studies evaluating the relative risk of TNF antagonists compared to such a standard population are not currently available. TNF antagonists are commonly used among patients who differ from the general population by demographic characteristics and who have conditions that are frequently complicated by co-morbidities or additional medications that in themselves increase the risk of TB compared to the general population [4, 101]. This renders direct comparisons of incidence invalid if the purpose is to isolate the contribution of TNF antagonists to that incidence.

Given the critical role of TNF in the pathogenesis of $\mathrm{TB}$, it should not be surprising that any TNF antagonist treatment might increase the risk of progression from a pre-existing latent infection with $M$. tuberculosis to clinically manifest TB. However, the relative risk of 4 among patients with rheumatoid arthritis receiving any of the compounds from the entire 


\begin{tabular}{|c|c|c|c|c|c|c|c|c|c|c|c|c|c|c|c|c|c|c|c|c|c|c|}
\hline 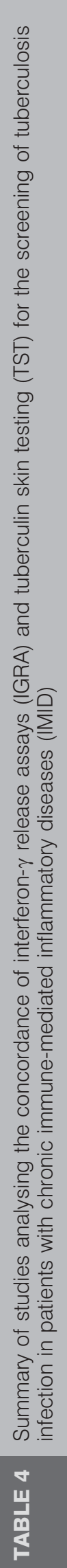 & 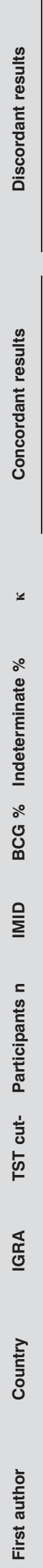 & 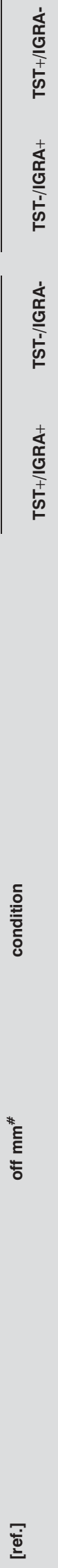 & 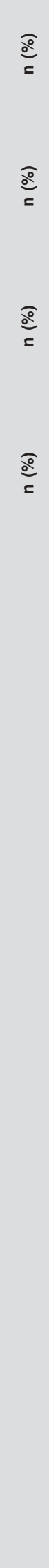 & 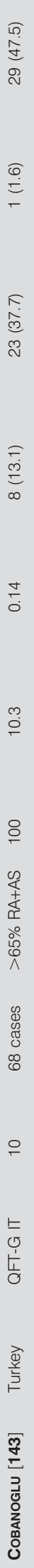 & $\begin{array}{l} \\
\\
\\
\frac{\infty}{0} \\
\frac{0}{\underline{t}} \\
\\
0 \\
\infty \\
0\end{array}$ & 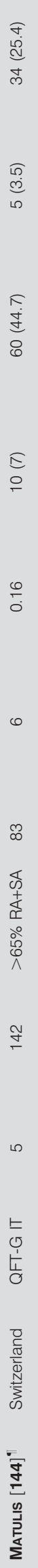 & 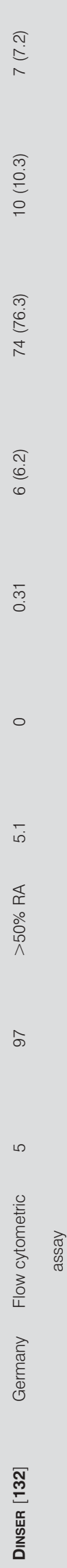 & 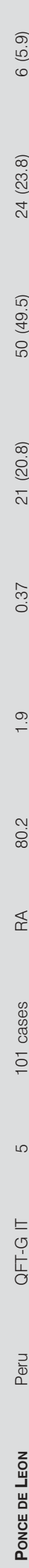 & 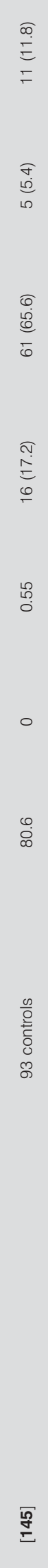 & 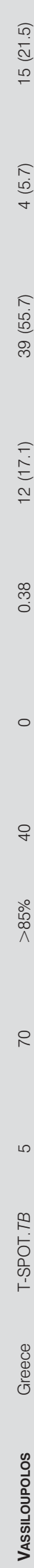 & 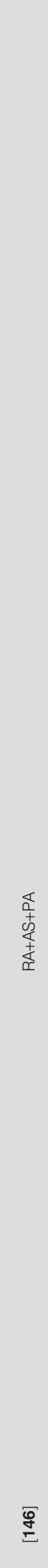 & 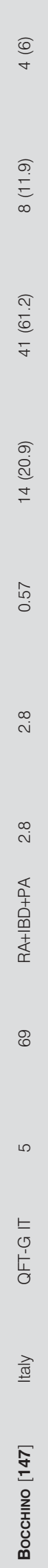 & 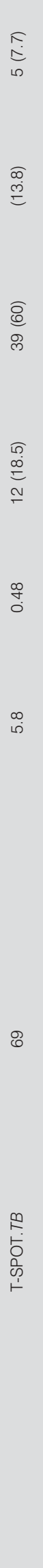 & 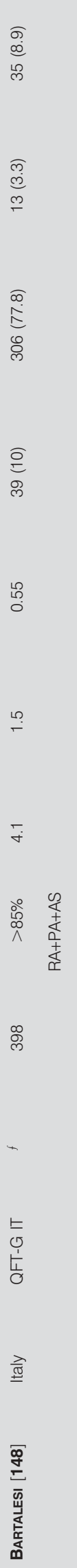 & $\begin{array}{l}\llcorner \\
\\
\\
\frac{m}{\sigma} \\
0 \\
\frac{0}{2} \\
\vec{w}\end{array}$ & 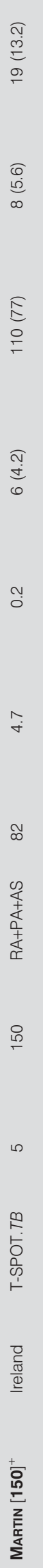 & $\begin{array}{l}\frac{1}{1} \\
\frac{1}{0}\end{array}$ & 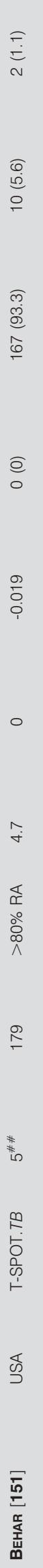 & 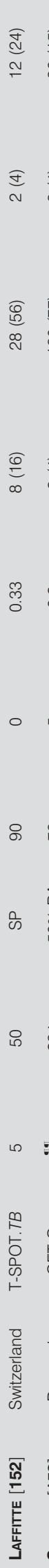 & 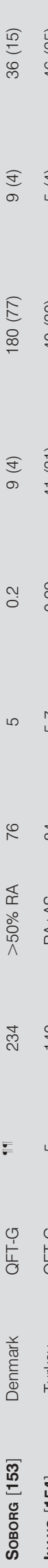 & $\begin{array}{l}\text { F } \\
\underline{\underline{H}} \\
\underline{0} \\
\underline{\underline{z}} \\
\underline{\underline{u}}\end{array}$ & 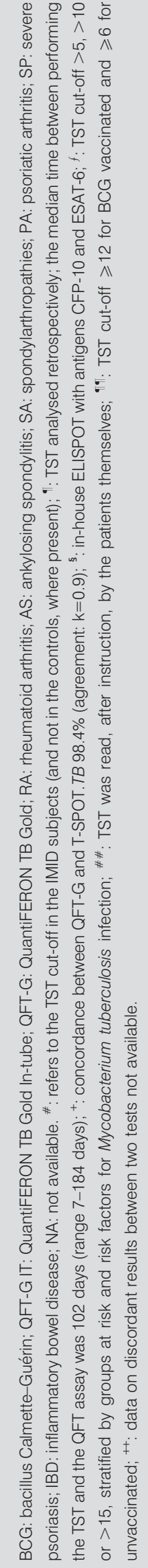 \\
\hline
\end{tabular}


class compared to those not receiving it was, nevertheless, remarkably modest in a comprehensive study in Sweden [4].

\section{Differences in TB risk by type of TNF antagonist}

Epidemiologically more meaningful, despite remaining methodological problems, have been intra-class comparisons, evaluating the relative impact on TB incidence by type of compound. The incidence rate ratio during the first 90 days of treatment (to exclude super-imposed recent infection), was approximately nine-fold among US patients [39]. However, drawing definite conclusions about the risk difference remains potentially biased because the conditions differ for which the two agents are preferentially prescribed.

\section{General criteria to define indication for preventive chemotherapy}

An objective strategy to define patient categories for whom preventive therapy should routinely be considered takes the remaining life-time risk relative to expected toxicity from the intervention into account, e.g. children have a larger life-time risk and tolerate drugs better than adults.

A second consideration concerns adults. Among these, a critical threshold relative risk warranting preventive chemotherapy, compared to persons with a long-lasting infection (in whom preventive chemotherapy is not recommended as a routine) should be defined. This seems to be largely absent from relevant statements and position papers. The American Thoracic Society recommends that persons with a recently acquired infection warrant preventive chemotherapy at any age [157] as does the British Thoracic Society [158]. The relative risk of progression to TB in a recently infected person is $\sim 10$ fold increased compared to that in a person with a longstanding infection. Implicitly and explicitly, patients with equal or stronger risk factors (patients with fibrotic lesions, diabetes, silicosis, HIV infection, etc.) are thus eligible for preventive chemotherapy irrespective of their age. Patients with weaker, but nevertheless recognised risk factors (such as smoking or underweight) are not generally considered for preventive chemotherapy, although the American Thoracic Society remains ambiguous on the issue of age [157].

\section{Consequences for preventive chemotherapy among patients treated with TNF antagonists}

No properly designed, population-based study has ever demonstrated a relative risk of TB in excess of 10 among patients treated with etanercept, even if the comparison group was the general population. The indication for preventive therapy with soluble TNF fusion protein is thus, compared with other risk factors that are clearly warranting preventive therapy, much less convincing. However, should the differential analysis [39] on the two main classes of TNF antagonists hold true, then monoclonal antibody-based TNF antagonists entail a relatively higher risk of progression from latent infection to active $\mathrm{TB}$ than patients receiving a soluble receptor-based compound.

In addition, given that the patient population receiving TNF antagonists commonly has an underlying risk that is elevated compared to the general population, patients started on therapy with TNF antagonists warrant strong consideration for preventive chemotherapy.

\section{Type and duration of preventive chemotherapy for persons treated with TNF antagonists}

There is no clinical trial evidence but information from a carefully conducted observational study has determined the effectiveness of preventive chemotherapy in this population $[14,115]$. In this study from Spain, after implementation of official recommendations to prescribe isoniazid preventive therapy for 9 months, the incidence rate of TB was reduced by $80 \%$ compared to the period prior to the recommendations. However, the confidence intervals for the risk reduction were very large because of the small number of events [14]. Concerns have been raised that treatment with TNF antagonists may result in an immune reconstitution syndrome similar to that observed among patients treated with antiretroviral therapy $[159,160]$. It is not known to what extent and whether such observation should influence treatment decisions with preventive chemotherapy.

\section{Summary}

In summary, implementation of local guidelines tailored to background to deal with latent infection with $M$. tuberculosis before starting TNF antagonists significantly decreases the number of active TB cases during treatment (evidence level C). Treatment of latent infection with $M$. tuberculosis for 9 months with $300 \mathrm{mg}$ of isoniazid daily is recommended by most national guidelines and the US Centers for Disease Control and Prevention. In this case, delaying the start of TNF antagonists for 4 weeks is a safe approach (evidence level D).

\section{SPECIAL CONSIDERATIONS IN CHILDREN}

As increasing numbers of children are successfully treated with TNF antagonists, mainly for juvenile idiopathic arthritis and Crohn's disease, we have also gained more experience with regards to the frequency of adverse drug events with their use [161]. In adults there is compelling evidence of increased rates of TB and this has been translated into similar concerns and a belief that the same risk is true for children. This, however, is not substantiated by relevant scientific publications, and there is a distinct lack of good surveillance data in children, unlike adults, on adverse drug events and infection risk of long-term TNF antagonist treatment.

Most evidence has accumulated around the use of etanercept, which has proven efficacy in juvenile idiopathic arthritis. Initial trials found no documented cases of TB [162] and more recent long-term follow-up has confirmed that very few cases occur. The largest, a German registry of 504 children followed for $>1$ yr [163], as well as a Dutch registry of 146 children followed for up to 4 yrs [164] and a US study of 69 children, 26 of whom completed 8-yr follow-up [165], revealed only two children developed TB on etanercept. One, a 9-yr-old female from the UK developed TB septic arthritis [166], the other a 9yr-old female from the Netherlands initially received etanercept, then infliximab after which she developed extrapulmonary TB [167]. There are even fewer published data regarding the use of infliximab in juvenile idiopathic arthritis and in inflammatory bowel disease [168, 169] with, however, only one documented case of a child developing TB whilst on infliximab for juvenile idiopathic arthritis [170]. Adaluzimab and abatacept have so far only included trials with $<200$ children with juvenile idiopathic arthritis, but they had relatively short 
follow-up. No cases of TB have been reported [171]. The existing data support a clear difference in the risk of developing TB between adults and children who receive TNF antagonist therapies in industrialised countries. This is likely to result from the lower prevalence of latent infection with $M$. tuberculosis in these children compared to adults, and not because they are less likely to reactivate $M$. tuberculosis where it is present. Because they are perceived as having a low risk, children are not always screened for latent infection with $M$. tuberculosis prior to embarking on TNF antagonist therapy.

\section{Diagnosis of TB/latent infection with M. tuberculosis in children}

The diagnosis of TB in any young child is difficult, due to the nature of primary childhood $\mathrm{TB}$, the paucity of bacteria and the inability of most children to produce sputum [172]. Using a positive tuberculin skin test as the diagnostic marker for latent infection in young children is unreliable because of the possible interference with a more recent BCG immunisation and the higher percentage of anergy in young children, even if not receiving immunosuppressive therapy. Current data suggest that IGRA are probably more accurate in diagnosing latent infection in children than the skin test. They do, however, seem to perform relatively poorly in children with (recent) active disease. Moreover there are insufficient data regarding the reliability of IGRA in children $<2$ yrs of age [173-175].

\section{Immunodiagnostic performance in immunosuppressed children}

Over the past decade we have learnt that genetic defects in Tcell mediated immune pathways impose a higher risk of developing mycobacterial disease [172], but such defects are rare. The tuberculin skin test is recognised to be unreliable if there is immunosuppression such as might be the case with corticosteroid therapy or in children with measles, varicella or with HIV-infection. Most recent studies assessing the performance of the newer immunodiagnostics in immunosuppressed children are carried out in HIV-infected children in high incidence settings, which is arguably not the most appropriate model for children receiving TNF antagonists or representing rates of latent infection in Europe.

One recent study suggests that the QuantiFERON TB Gold intube assay (Cellestis Ltd) does not provide a determinate result in a substantial proportion of children with a variety of primary and acquired immunodeficiencies, including children treated for auto-inflammmatory disorders [176].

\section{Current practice}

There are currently no published (inter)national guidelines for TB screening for children about to embark on TNF antagonist therapy. However, most institutions have developed local protocols, usually modelled on adult guidelines.

\section{Summary}

In summary, there appears to be a smaller risk of developing mycobacterial disease in children receiving TNF antagonist therapies than in adults, most probably explained by the fact that latent infection with $M$. tuberculosis is more prevalent amongst adults in countries where these therapies are given. A risk assessment on the basis of country of origin, known TB contacts, travel history and age, still remains the important cornerstone of the diagnosis of infection with $M$. tuberculosis in children. Combining results of both tuberculin skin tests and IGRA may yield more accurate information, although there are currently no validated "scoring-systems" available for children and herein age seems to be an important confounder. The current paucity of available paediatric information makes it imperative that data are collected, and an international effort in this direction will certainly lead to better understanding and more knowledge in this field.

\section{PUBLISHED NATIONAL GUIDELINES}

Since the recognition of an increased risk of reactivating TB with TNF antagonist treatment for inflammatory diseases, guidance for clinicians has been produced in several countries. This guidance has taken various forms from comprehensive evidence based guidelines (UK) to short statements of suggested practice (USA). Eight such statements or guidelines, published between 2003 and 2009, have been identified and are discussed and compared on factors affecting risk, definition of latent infection with $M$. tuberculosis, those eligible for preventive chemotherapy and recommended regimens, and time delay before commencement of TNF antagonist therapy. These publications are from the following countries: France [116], Germany [177], Ireland [117], Portugal [107], Spain (as outlined in [7, 115]), Switzerland [20], UK [113] and USA [114]. In addition, other national guidelines have recently become available in non-English languages, e.g. in Denmark.

The French publication is a response to the preliminary consensus guidelines elaborated at the Advances in targeted therapies IV meeting in 2002 [178], and is based on proposals by a multidisciplinary French co-operative group published in 2002 [179]. The Spanish documents published in 2003 and 2005 $[7,115]$ outline the measures initially proposed in 2002 by the Spanish Rheumatologic Society and the Spanish Health authority. Later on-line guidelines have become available in Spanish [180]. The Swiss recommendations are the result of a multidisciplinary workshop and are supported by a more recent article reviewing the indications and cautions before using TNF antagonists in patients with inflammatory bowel disease [181]. The US publication is not a guideline as such but a series of nine recommendations and refers to broader American Thoracic Society guidelines on tuberculin testing and treatment of latent infection with $M$. tuberculosis and TB. A summary of the main recommendations made in the different publications and in this TBNET consensus statement can be found in table 5 .

\section{Points of agreement}

All guidelines recommend that every patient considered for TNF antagonist therapy should be screened for evidence of latent infection with M. tuberculosis or TB. A full clinical history and physical examination should be part of the initial assessment. This should include details of ethnicity, country of birth, history of recent exposure to $\mathrm{TB}$, previous $\mathrm{TB}$ and treatment, together with any additional risk such as substance abuse. All patients should have a chest radiograph with either a tuberculin skin test or IGRA as investigations for evidence of latent infection. Several documents stress that even with a negative tuberculin skin test or IGRA, a history of past 


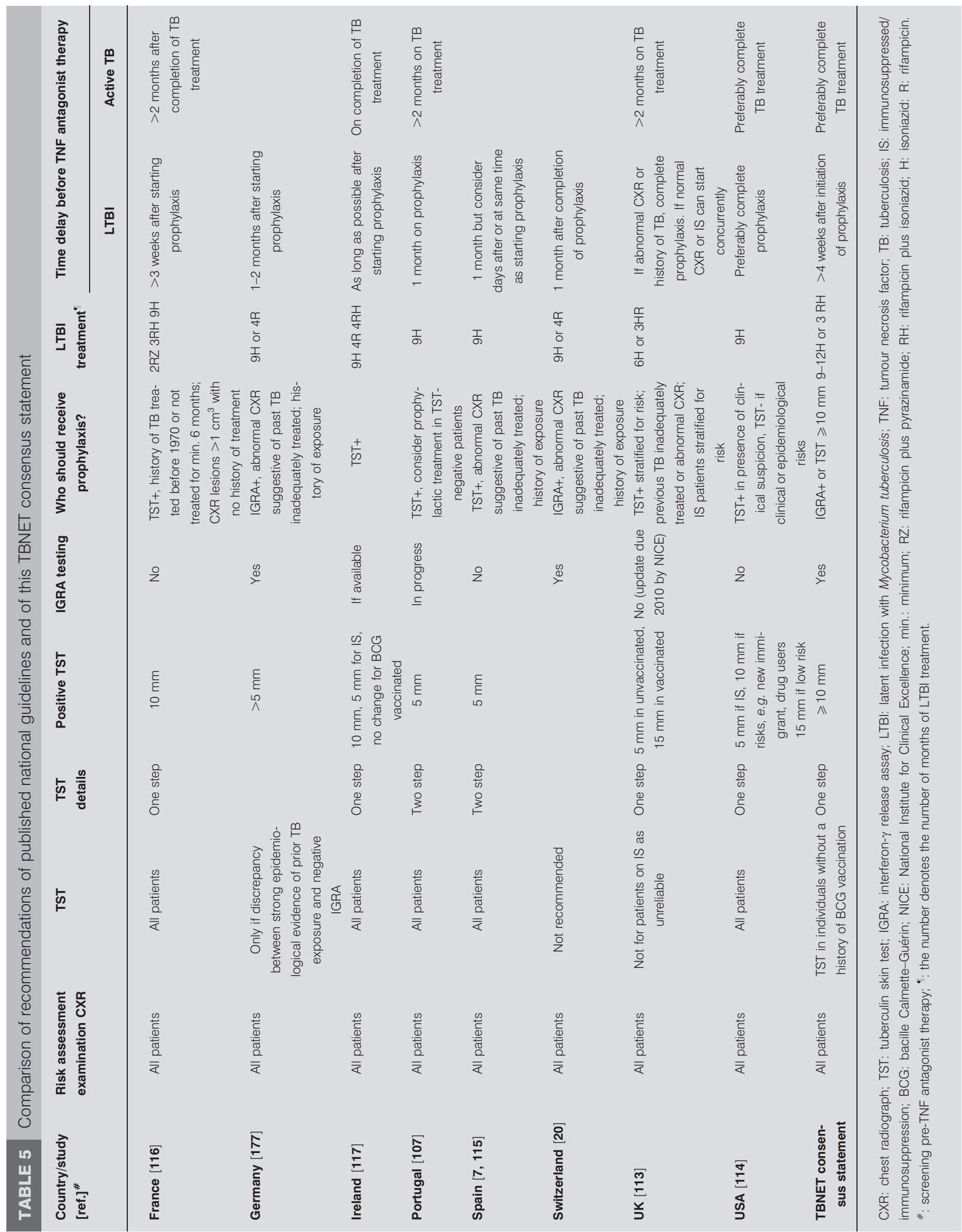


exposure or untreated TB should be an indication for preventive therapy. All recommend a whole course of treatment for active $\mathrm{TB}$ where present and preventive chemotherapy when latent infection with $M$. tuberculosis is diagnosed. The importance of maintaining vigilance for TB in all patients on TNF antagonist treatment is emphasised, even after a full course of preventive therapy has been completed.

\section{Areas of difference}

Guidelines for the diagnosis of latent infection with $M$. tuberculosis and recommendations for preventive chemotherapy regimens are not always consistent between different countries. Most guidelines except those from Switzerland and Germany recommend a tuberculin skin test for screening. Switzerland recommends using any of the two commercially available IGRA tests instead of the tuberculin skin test based on evidence by SELLAM et al. [182]. The German guidelines recommend using the tuberculin skin test only when proven exposure to an infectious case is not supported by a positive IGRA. The Portuguese guidelines are due to be updated and it is expected that a position for IGRA testing will be included for the first time. In the UK, the National Institute for Clinical Excellence will be publishing an evidence-based assessment for IGRA testing pre-TNF antagonist therapy in late 2010.

Interpretation of the tuberculin skin test result differs depending on the cut-off measurements for the intradermal test defining positivity, on the immune status of the patient and the likelihood of latent infection with $M$. tuberculosis based on previous exposure (table 5). Some guidelines recommend repeating the tuberculin skin test to increase test sensitivity. The Portuguese guidelines recommend skin testing before initiating any immunosuppressive treatment and then repeating screening prior to TNF antagonist therapy. Immunosuppression is defined as established disease, or treatment with corticosteroids of $>10 \mathrm{mg} \cdot \mathrm{day}^{-1}$, methotrexate, cyclosporine, azathioprine, leflunomide or cyclophosphamide.

There are variations in the recommended preventive therapy regimens (table 5). In particular, the French guidelines are the only one to include the combination of rifampicin plus pyrazinamide as a possible regimen (table 5). Most countries, however, no longer use this combination due to the high incidence of severe drug-induced hepatic injury [183]. Further variations are found in the time suggested for both preventive chemotherapy and treatment for active disease before commencing therapy with TNF antagonists, varying from 3 weeks after initiation of preventive therapy to its completion, and 2 months after initiation of curative treatment to completion of therapy. The French guidelines are also unique in recommending long-term preventive therapy if TNF antagonist treatment is used at all after completion of treatment for active disease. The UK guidelines are probably the most comprehensive and cover several different clinical scenarios. Unique to these guidelines is an attempt to quantify risk of both reactivating TB and drug-induced hepatitis. In addition, according to the UK guidelines those with previously treated TB should continue to be monitored at 3-months intervals while on TNF antagonist therapy.

\section{Summary}

In summary, all eight national guidelines agree that every patient considered for TNF antagonist therapy should be screened for evidence of $\mathrm{TB}$, and where absent for latent infection. Investigations should include a chest radiograph with either a tuberculin skin test or an IGRA. A history of significant past exposure or untreated TB should be an indication for preventive chemotherapy even when tests for latent infection are negative. Recommended preventive chemotherapy regimens vary and include 6 or 9 months with isoniazid, 3 months of rifampicin plus isoniazid, and 4 months of rifampicin. There are variations in the recommendation for the duration of both preventive chemotherapy and treatment of active disease before commencing TNF antagonist therapy.

\section{CONSENSUS RECOMMENDATIONS}

The currently available evidence on the best management to prevent TB in patients receiving TNF antagonist therapies is limited. The recommendations summarised in this article represent a consensus of published evidence (for evidence levels see table 1) and expert opinions to guide physicians to evaluate the risk for TB and to prevent TB in patients with $M$. tuberculosis specific immune responses who are candidates for therapies with TNF antagonists. These recommendations shall be valid until further clinical evidence is available.

\section{Who should be screened for latent infection with M. tuberculosis prior to treatment with monoclonal antibodies against TNF?}

Prior to antibody-based anti-TNF therapies all candidates should be screened for the presence of $M$. tuberculosis specific immune responses (the best available proxy for latent infection with $M$. tuberculosis; evidence level C). All candidates for TNF antagonist therapies should be questioned about a history of prior TB or TB contact and should have a chest radiograph to search for evidence of prior or active TB.

\section{Are persons receiving treatment with soluble TNF receptor- based antagonists with positive $\mathrm{M}$. tuberculosis-specific immune responses also at increased risk of developing TB?} The risk of $\mathrm{TB}$ is increased in adults with positive $M$. tuberculosis specific immune responses (latent infection with $M$. tuberculosis) being treated with etanercept, a TNF receptor fusion protein. However, this risk of developing TB (given latent infection) has been shown to be lower in these individuals compared to individuals with latent infection with M. tuberculosis who are being treated with monoclonal antibodies against TNF (evidence level C).

\section{Should preventive therapy against TB be advised for all candidates undergoing TNF antagonist therapies with $\mathrm{M}$. tuberculosis-specific immune responses (latent infection with M. tuberculosis)?}

Preventive chemotherapy against TB should be offered to all individuals before undergoing TNF antagonist therapies, including patients who receive etanercept, in the presence of evidence of latent infection with $M$. tuberculosis (evidence level C).

\section{Is different management recommended based on different underlying diseases?}

Screening for latent infection and preventive chemotherapy against TB should not be different for patients with different underlying disease (rheumatoid arthritis, psoriasis or inflammatory 
bowel disease) who are candidates for TNF antagonist therapies (evidence level D).

Should latent infection with M. tuberculosis be diagnosed based on tuberculin skin testing, IGRA testing or both?

In general, IGRAs are superior to the tuberculin skin test in detecting anti-mycobacterial immune responses in immunocompromised individuals. In addition, mitogen controls in the IGRAs give an advantage over the tuberculin skin test as they can be used for discrimination between anergy and true negative-antigen specific immune responses. However, the only evidence available is that a positive result in a two-step tuberculin skin test predicts the development of TB in individuals undergoing TNF antagonist therapies. As IGRAs have not been evaluated in this context, the evidence is essentially indirect.

At this stage, the choice of immunodiagnostic test to detect latent infection with $M$. tuberculosis prior to TNF antagonist therapies is unclear. Published clinical evidence favours twostep tuberculin skin testing while expert opinion suggests that IGRAs are superior to the tuberculin skin test in identifying individuals at risk of developing TB.

For the diagnosis of $M$. tuberculosis specific immune responses (latent infection with $M$. tuberculosis) expert opinion suggests using the QuantiFERON TB Gold in-tube test or the TSPOT.TB test (Oxford Immunotech) or, as an alternative, tuberculin skin testing in individuals without a history of BCG vaccination.

Moreover, paediatric practice suggests concomitantly using all three, tuberculin skin test, IGRA and chest radiography, and any positive result taken as evidence for latent infection, after exclusion of active TB. Where negative, however, these tests have a poor predictive value on their own (Evidence levels C and D).

If the tuberculin skin test is used for the diagnosis of latent infection with $\mathrm{M}$. tuberculosis prior to the initiation of TNF antagonist therapies, should a two-step approach be considered?

At present, as there is limited evidence that sensitivity for true latent infection with $M$. tuberculosis is increased among persons who respond to a tuberculin skin test booster (but considerable evidence is available to show that this reduces specificity), the two-step approach is not generally recommended for the diagnosis of latent infection with $M$. tuberculosis prior to the initiation of TNF antagonist therapies, although some national guidelines, e.g. Spanish guidelines, do recommend it based on empirical evidence (evidence level C).

If IGRAs are used for the diagnosis of latent infection with $M$. tuberculosis prior to the initiation of TNF antagonist therapies is there a preference for QuantiFERON TB Gold in-tube or T-SPOT.TB test in this specific situation?

Although there is some evidence of increased sensitivity of the T-SPOT.TB test (Oxford Immunotech) over QuantiFERON TB Gold in-tube test (Cellestis Ltd) in severely immunocompromised patients in diagnosing $M$. tuberculosis specific immune responses (latent infection with $M$. tuberculosis), current clinical evidence from cross sectional and cohort studies, including patients undergoing TNF antagonist therapies does not clearly favour one test over the other. Both tests are advocated for the diagnosis of latent infection prior to the initiation of TNF antagonist therapies (evidence level D).

\section{Which cut-offs should be used for the tuberculin skin test and IGRAs for the diagnosis of latent infection with $M$. tuberculosis prior to the initiation of TNF antagonist therapies?}

For the tuberculin skin test, there is evidence that the loss in sensitivity by increasing the cut-off point from 5 to $10 \mathrm{~mm}$ to denote infection is marginal while there is a substantial gain in specificity. A tuberculin skin test cut-off of $\geqslant 10 \mathrm{~mm}$, as generally recommended for other immunocompromised conditions (excluding HIV-infection) warranting preventive chemotherapy against $\mathrm{TB}$, seems to be the most appropriate for the diagnosis of latent infection with $M$. tuberculosis prior to the initiation of TNF antagonist therapies. A tuberculin skin test result of $\geqslant 10 \mathrm{~mm}$ should not generally need confirmation by an IGRA.

Paediatric consensus is to provide preventive chemotherapy if either the IGRA or the tuberculin skin test is positive and if only the tuberculin skin test is used, different cut-offs should be used for BCG-vaccinated ( $\geqslant 10 \mathrm{~mm}$ ) versus non-vaccinated $(\geqslant 5 \mathrm{~mm})$ children, taking epidemiological risk factors into account (evidence level C).

The cut-offs for IGRAs for the diagnosis of latent infection with $M$. tuberculosis prior to the initiation of TNF antagonist therapies should be used as recommended by the manufacturers for Europe (evidence level D).

\section{What decision should be taken when testing for latent infection yields discordant results prior to the initiation of TNF antagonist therapies?}

The role of patient history, origin and prior BCG vaccination status should guide interpretation of test results. IGRA tests should be preferred over tuberculin skin testing in individuals with a known history of BCG vaccination whenever possible. In individuals without a history of BCG vaccination, one positive test result (either tuberculin skin test or IGRA) should qualify for the individual to undergo preventive therapy (evidence level D).

\section{When should TNF antagonist therapies be initiated following the induction of preventive chemotherapy against TB?}

An induction period of 4 weeks is considered safe by most experts to start TNF antagonist therapy following the induction of preventive chemotherapy against TB (evidence level D).

\section{Which preventive chemotherapy regimen is the most effective in reducing the risk of developing TB in individuals with $\mathrm{M}$. tuberculosis-specific immune responses undergoing TNF antagonist therapies?}

Effectiveness of different chemotherapeutic regimens to prevent TB in individuals with $M$. tuberculosis specific immune responses undergoing TNF antagonist therapies has not been evaluated. The best clinical evidence of efficacy (evidence level A) in other populations supports a choice between two preventive therapy regimens: 12 months of isoniazid and 
3 months of isoniazid plus rifampicin. The efficacy of both regimens exceeds $90 \%$. However, in most countries 9 months isoniazid regimens are currently recommended to prevent TB in individuals with latent infection. Alternative regimens with likely lower efficacy and effectiveness, but reduced incidence of significant adverse drug events, are isoniazid for 6 months (which is recommended in the UK) or rifampicin for 4 months. The probability of developing active TB is substantially increased when adherence to guidelines for preventive chemotherapy against TB in individuals receiving TNF antagonist therapies is not strict.

\section{How should patients who started preventive chemotherapy against TB be followed especially in relation to the initiation of TNF antagonist therapies?}

Patients should be educated about early signs and symptoms of TB and possible adverse drug events of the medication used for preventive therapy. Routine follow-up with chest radiography is not indicated in asymptomatic individuals treated with preventive chemotherapy against TB. However, In the presence of signs and symptoms compatible with active TB, chest radiography should be performed without delay. In cases of doubt, chest computer tomography scans should be performed, which are superior to chest radiography in detecting early radiological signs of active TB. Liver enzymes should be analysed prior to the initiation of preventive chemotherapy and may be re-evaluated every 3-4 weeks on treatment, or if the patient becomes symptomatic. Repeated testing for latent infection with $M$. tuberculosis (every year) may be considered in persons with ongoing risks of TB exposure (travel, work, etc.), but is not recommended to be done with the tuberculin skin test as results might be distorted by boosting (evidence level D).

\section{When shall treatment with TNF antagonists be initiated (if indicated) in patients with active TB?}

The optimal time-point for the initiation of treatment with TNF antagonists in individuals who are being treated for active TB is unclear. Expert opinion suggests to preferably initiate treatment with TNF antagonists when a full course of antiTB treatment, according to international standards, has been completed (evidence level D).

\section{Are patients with a history of TB, who have been adequately treated, at increased risk for TB reactivation when they receive TNF antagonist therapies?}

Patients who have completed appropriate TB therapy do not appear to have an increased risk of TB when TNF antagonist therapy is started. Currently, preventive chemotherapy is not generally recommended for patients with positive $M$. tuberculosis-specific immune responses undergoing TNF antagonist therapies who have been adequately treated against $\mathrm{TB}$ in the past, unless re-infection with $M$. tuberculosis is plausible (evidence level D).

\section{What is the optimal duration of anti-TB chemotherapy for patients who developed TB in relation to TNF antagonist therapies?}

The optimal duration of anti-TB chemotherapy for patients who developed TB in relation to TNF antagonist therapies has not been defined. There is no evidence that the duration of
anti-TB treatment needs to be prolonged, if TB developed in relation to TNF antagonist therapies (evidence level D).

\section{CONCLUSIONS}

The introduction of TNF antagonist therapies into clinical practice has been a breakthrough in the history of the treatment of inflammatory diseases such as rheumatoid arthritis, psoriatic arthritis, ankylosing spondylarthritis, juvenile idiopathic arthritis and inflammatory bowel disease. Blocking the action of TNF by anti-TNF antibodies or by a soluble TNF receptor leads to an inhibition of the pathological inflammatory process at multiple levels and it is currently the most effective treatment modality for these diseases.

A concerning common adverse event of TNF antagonist therapies is the reactivation of latent infection with $M$. tuberculosis. In this TBNET consensus statement we have summarised the current knowledge of the risk of TB in relation to TNF antagonist therapies and have provided detailed consensus recommendations for the most important clinical questions related to TB and TNF antagonist therapies in adults and children.

TB screening and preventive chemotherapy for all individuals with latent infection with $M$. tuberculosis should become the standard of care for all individuals undergoing TNF antagonist therapies. Following the guidelines of this article will lead to a significant reduction in the number of cases of active $\mathrm{TB}$ in relation to TNF antagonist therapies.

\section{STATEMENT OF INTEREST}

Statements of interest for J.J. Gomez-Reino, H.J. Milburn, R.S. Walis, D. Goletti, R. Diel, L. Carmona, F. Bartalesi, P. Ravn and C. Lange can be found at www.erj.ersournals.com/site/misc/statements.xhtml

\section{ACKNOWLEDGEMENTS}

The affiliation details are as follows. I. Solovic: Catholic University, Ružomberok, Slovakia. M. Sester: Saarland University, Hamburg, Germany. J.J. Gomez-Reino: Hospital Clinico Universitario, Santiago de Compostela, Spain. H.L. Rieder: International Union against Tuberculosis and Lung Disease, Kirchlindach, Switzerland. S. Ehlers and C. Lange: Research Center Borstel, Borstel, Germany. H.J. Milburn and R. Groves: Guy's and St Thomas Hospital, London, UK. B. Kampmann: Imperial College, London, UK. B. Hellmich: Kreiskrankenhaus Plochingen, Plochingen, Germany. S. Schreiber: Christian Albrechts University, Kiel, Germany. R.S. Wallis: Pfizer, New London, CT, USA. G. Sotgiu: Sassari University, Sassari, Italy. E.H. Schölvinck: University Medical Centre Groningen, Groningen, the Netherlands. D. Goletti: National Institute for Infectious Diseases L. Spallanzani, Rome, Italy. J.P. Zellweger: Swiss Lung Association, Berne, Switzerland. R. Diel: Hanover Medical School, Hanover, Germany. L. Carmona: Sociedad Española de Reumatologia, Madrid, Spain. F. Bartalesi: Careggi Hospital, Florence, Italy. P. Ravn: University Hospital Herlev, Herlev, Denmark. A. Bossink: Diakonessenhuis, Utrecht, the Netherlands. R. Duarte: Centro de Diagnóstico Pneumológico, Vila Nova de Gaia, Portugal. C. Erkens: KNCV Tuberculosis Foundation, The Hague, the Netherlands. J. Clark: Newcastle General Hospital, Newcastle upon Tyne, UK. G.B. Migliori: Fondazione S. Maugeri, Care and Research Institute, Tradate, Italy.

All authors contributed equally to writing this series article. Each section was written by the authors who are specialists within that field. The lead author of each section, respectively, was as follows: C. Lange, S. Ehlers, B. Hellmich, S. Schreiber, R. Groves, J.J. Gomez-Reino, M. Sester, H.L. Rieder, B. Kampmann, H.J. Milburn, G.B. Migliori and I. Solovic. 


\section{REFERENCES}

1 Baud V, Karin M. Signal transduction by tumor necrosis factor and its relatives. Trends Cell Biol 2001; 11: 372-377.

2 Hehlgans T, Pfeffer K. The intriguing biology of the tumour necrosis factor/tumour necrosis factor receptor superfamily: players, rules and the games. Immunology 2005; 115: 1-20.

3 Wajant H, Pfizenmaier K, Scheurich P. Tumor necrosis factor signaling. Cell Death Differ 2003; 10: 45-65.

4 Askling J, Fored CM, Brandt L, et al. Risk and case characteristics of tuberculosis in rheumatoid arthritis associated with tumor necrosis factor antagonists in Sweden. Arthritis Rheum 2005; 52 : 1986-1992.

5 Dixon WG, Watson $\mathrm{K}$, Lunt $\mathrm{M}$, et al. Rates of serious infection, including site-specific and bacterial intracellular infection, in rheumatoid arthritis patients receiving anti-tumor necrosis factor therapy: results from the British Society for Rheumatology Biologics Register. Arthritis Rheum 2006; 54: 2368-2376.

6 Ellerin T, Rubin RH, Weinblatt ME. Infections and anti-tumor necrosis factor alpha therapy. Arthritis Rheum 2003; 48: 30133022.

7 Gomez-Reino JJ, Carmona L, Valverde VR, et al. Treatment of rheumatoid arthritis with tumor necrosis factor inhibitors may predispose to significant increase in tuberculosis risk: a multicenter active-surveillance report. Arthritis Rheum 2003; 48: 21222127.

8 Flynn JL, Chan J. Immunology of tuberculosis. Annu Rev Immunol 2001; 19: 93-129.

9 Kaufmann SHE, Cole ST, Mizrahi V, et al. Mycobacterium tuberculosis and the host response. J Exp Med 2005; 201: 16931697.

10 Ehlers S. Tumor necrosis factor and its blockade in granulomatous infections: differential modes of action of infliximab and etanercept? Clin Infect Dis 2005; 41: Suppl. 3, S199-S203.

11 Wolfe F, Michaud K, Anderson J, et al. Tuberculosis infection in patients with rheumatoid arthritis and the effect of infliximab therapy. Arthritis Rheum 2004; 50: 372-379.

12 Wallis RS, Broder M, Wong J, et al. Granulomatous infections due to tumor necrosis factor blockade: correction. Clin Infect Dis 2004; 39: 1254-1255.

13 Keane J, Gershon S, Wise RP, et al. Tuberculosis associated with infliximab, a tumor necrosis factor alpha-neutralizing agent. New Engl J Med 2001; 345: 1098-1104.

14 Gomez-Reino JJ, Carmona L, Angel Descalzo M. Risk of tuberculosis in patients treated with tumor necrosis factor antagonists due to incomplete prevention of reactivation of latent infection. Arthritis Rheum 2007; 57: 756-761.

15 Pai M, Zwerling A, Menzies D. Systematic review: T-cell-based assays for the diagnosis of latent tuberculosis infection: an update. Ann Intern Med 2008; 149: 177-184.

16 Mori $T$. Usefulness of interferon-gamma release assays for diagnosing TB infection and problems with these assays. J Infect Chemother 2009; 15: 143-155.

17 Richeldi L, Losi M, D'Amico R, et al. Performance of tests for latent tuberculosis in different groups of immunocompromised patients. Chest 2009; 136: 198-204.

18 Diel R, Loddenkemper R, Meywald-Walter K, et al. Predictive value of a whole blood IFN-gamma assay for the development of active tuberculosis disease after recent infection with Mycobacterium tuberculosis. Am J Respir Crit Care Med 2008; 177: 1164-1170.

19 Diel R, Hauer B, Loddenkemper R, et al. [Recommendations for tuberculosis screening before initiation of TNF-alpha-inhibitor treatment in rheumatic diseases.] Pneumologie 2009; 63: 329-334.

20 Beglinger C, Dudler J, Mottet C, et al. Screening for tuberculosis infection before the initiation of an anti-TNF-alpha therapy. Swiss Med Wkly 2007; 137: 620-622.
21 Wallis RS. Infectious complications of tumor necrosis factor blockade. Curr Opin Infect Dis 2009; 22: 403-409.

22 Bekker LG, Freeman S, Murray PJ, et al. TNF-alpha controls intracellular mycobacterial growth by both inducible nitric oxide synthase-dependent and inducible nitric oxide synthase-independent pathways. J Immunol 2001; 166: 6728-6734.

23 Kindler V, Sappino AP, Grau GE, et al. The inducing role of tumor necrosis factor in the development of bactericidal granulomas during BCG infection. Cell 1989; 56: 731-740.

24 Mohan VP, Scanga CA, Yu K, et al. Effects of tumor necrosis factor alpha on host immune response in chronic persistent tuberculosis: possible role for limiting pathology. Infect Immun 2001; 69: 1847-1855.

25 Allendoerfer R, Deepe GS Jr. Blockade of endogenous TNF-alpha exacerbates primary and secondary pulmonary histoplasmosis by differential mechanisms. J Immunol 1998; 160: 6072-6082.

26 Havell EA. Evidence that tumor necrosis factor has an important role in antibacterial resistance. J Immunol 1989; 143: 2894-2899.

27 Roach DR, Bean AG, Demangel C, et al. TNF regulates chemokine induction essential for cell recruitment, granuloma formation, and clearance of mycobacterial infection. J Immunol 2002; 168: 4620-4627.

28 Mulligan MS, Vaporciyan AA, Miyasaka M, et al. Tumor necrosis factor alpha regulates in vivo intrapulmonary expression of ICAM-1. Am J Pathol 1993; 142: 1739-1749.

29 Flynn JL, Goldstein MM, Chan J, et al. Tumor necrosis factoralpha is required in the protective immune response against Mycobacterium tuberculosis in mice. Immunity 1995; 2: 561-572.

30 Olleros ML, Guler R, Vesin D, et al. Contribution of transmembrane tumor necrosis factor to host defense against Mycobacterium bovis bacillus Calmette-Guerin and Mycobacterium tuberculosis infections. Am J Pathol 2005; 166: 1109-1120.

31 Saunders BM, Tran S, Ruuls S, et al. Transmembrane TNF is sufficient to initiate cell migration and granuloma formation and provide acute, but not long-term, control of Mycobacterium tuberculosis infection. J Immunol 2005; 174: 4852-4859.

32 Filley EA, Rook GA. Effect of mycobacteria on sensitivity to the cytotoxic effects of tumor necrosis factor. Infect Immun 1991; 59: 2567-2572.

33 Moreira AL, Tsenova L, Aman MH, et al. Mycobacterial antigens exacerbate disease manifestations in Mycobacterium tuberculosisinfected mice. Infect Immun 2002; 70: 2100-2107.

34 Ehlers S, Kutsch S, Ehlers EM, et al. Lethal granuloma disintegration in mycobacteria-infected TNFRp55-/- mice is dependent on T cells and IL-12. J Immunol 2000; 165: 483-492.

35 Dalton DK, Haynes L, Chu CQ, et al. Interferon gamma eliminates responding $\mathrm{CD} 4 \mathrm{~T}$ cells during mycobacterial infection by inducing apoptosis of activated CD4 T cells. J Exp Med 2000; 192: 117-122.

36 Bean AG, Roach DR, Briscoe H, et al. Structural deficiencies in granuloma formation in TNF gene-targeted mice underlie the heightened susceptibility to aerosol Mycobacterium tuberculosis infection, which is not compensated for by lymphotoxin. J Immunol 1999; 162: 3504-3511.

37 Ehlers S, Holscher C, Scheu S, et al. The lymphotoxin beta receptor is critically involved in controlling infections with the intracellular pathogens Mycobacterium tuberculosis and Listeria monocytogenes. J Immunol 2003; 170: 5210-5218.

38 Roach DR, Briscoe H, Saunders B, et al. Secreted lymphotoxinalpha is essential for the control of an intracellular bacterial infection. J Exp Med 2001; 193: 239-246.

39 Wallis RS. Tumour necrosis factor antagonists: structure, function, and tuberculosis risks. Lancet Infect Dis 2008; 8: 601-611.

40 Scallon B, Cai A, Solowski N, et al. Binding and functional comparisons of two types of tumor necrosis factor antagonists. J Pharmacol Exp Ther 2002; 301: 418-426. 
41 Appel $\mathrm{H}$, Scheer $\mathrm{R}$, Haibel $\mathrm{H}$, et al. In vitro observations of $\mathrm{T}$ cell responsiveness to recall antigens during tumor necrosis factoralpha-blocking therapy in patients with ankylosing spondylitis. J Rheumatol 2007; 34: 2264-2270.

42 Hamdi $H$, Mariette $X$, Godot $V$, et al. Inhibition of antituberculosis T-lymphocyte function with tumour necrosis factor antagonists. Arthritis Res Ther 2006; 8: R114.

43 Saliu OY, Sofer C, Stein DS, et al. Tumor-necrosis-factor blockers: differential effects on mycobacterial immunity. J Infect Dis 2006, 194: 486-492.

44 Kirchner S, Holler E, Haffner S, et al. Effect of different tumor necrosis factor (TNF) reactive agents on reverse signaling of membrane integrated TNF in monocytes. Cytokine 2004; 28 67-74.

45 Shen C, Assche GV, Colpaert S, et al. Adalimumab induces apoptosis of human monocytes: a comparative study with infliximab and etanercept. Aliment Pharmacol Ther 2005; 21: 251-258.

46 ten Hove T, van Montfrans C, Peppelenbosch MP, et al. Infliximab treatment induces apoptosis of lamina propria $\mathrm{T}$ lymphocytes in Crohn's disease. Gut 2002; 50: 206-211.

47 Van den Brande JM, Braat H, van den Brink GR, et al. Infliximab but not etanercept induces apoptosis in lamina propria $\mathrm{T}$ lymphocytes from patients with Crohn's disease. Gastroenterology 2003; 124: 1774-1785.

48 Van den Brande JM, Koehler TC, Zelinkova Z, et al. Prediction of antitumour necrosis factor clinical efficacy by real-time visualisation of apoptosis in patients with Crohn's disease. Gut 2007 56: 509-517.

49 Bruns H, Meinken C, Schauenberg P, et al. Anti-TNF immunotherapy reduces CD8+ $\mathrm{T}$ cell-mediated antimicrobial activity against Mycobacterium tuberculosis in humans. J Clin Invest 2009, 119: 1167-1177.

50 Nesbitt A, Fossati G, Bergin M, et al. Mechanism of action of certolizumab pegol (CDP870): in vitro comparison with other anti-tumor necrosis factor alpha agents. Inflamm Bowel Dis 2007; 13: 1323-1332

51 Marino S, Sud D, Plessner H, et al. Differences in reactivation of tuberculosis induced from anti-TNF treatments are based on bioavailability in granulomatous tissue. PLoS Comp Biol 2007; 3 1909-1924.

52 Olleros ML, Vesin D, Lambou AF, et al. Dominant-negative tumor necrosis factor protects from Mycobacterium bovis bacillus Calmette Guerin (BCG) and endotoxin-induced liver injury without compromising host immunity to BCG and Mycobacterium tuberculosis. J Infect Dis 2009; 199: 1053-1063.

53 Spohn G, Guler R, Johansen P, et al. A virus-like particle-based vaccine selectively targeting soluble TNF-alpha protects from arthritis without inducing reactivation of latent tuberculosis. J Immunol 2007; 178: 7450-7457.

54 Feldmann M, Brennan FM, Williams RO, et al. The transfer of a laboratory based hypothesis to a clinically useful therapy: the development of anti-TNF therapy of rheumatoid arthritis. Best Prac Res Clin Rheumatol 2004; 18: 59-80.

55 Elliott MJ, Maini RN, Feldmann M, et al. Randomised doubleblind comparison of chimeric monoclonal antibody to tumour necrosis factor alpha (cA2) versus placebo in rheumatoid arthritis. Lancet 1994; 344: 1105-1110.

56 Chen YF, Jobanputra P, Barton P, et al. A systematic review of the effectiveness of adalimumab, etanercept and infliximab for the treatment of rheumatoid arthritis in adults and an economic evaluation of their cost-effectiveness. Health Technol Assess 2006; 10: iii-iv, xi-xiii, 1-229.

57 Saag KG, Teng GG, Patkar NM, et al. American College of Rheumatology 2008 recommendations for the use of nonbiologic and biologic disease-modifying antirheumatic drugs in rheumatoid arthritis. Arthritis Rheum 2008; 59: 762-784.
58 Mancarella L, Bobbio-Pallavicini F, Ceccarelli F, et al. Good clinical response, remission, and predictors of remission in rheumatoid arthritis patients treated with tumor necrosis factoralpha blockers: the GISEA study. J Rheumatol 2007; 34: 1670-1673.

59 Goekoop-Ruiterman YP, de Vries-Bouwstra JK, Allaart CF, et al. Comparison of treatment strategies in early rheumatoid arthritis: a randomized trial. Ann Intern Med 2007; 146: 406-415.

60 Combe B, Landewe R, Lukas C, et al. EULAR recommendations for the management of early arthritis: report of a task force of the European Standing Committee for International Clinical Studies Including Therapeutics (ESCISIT). Ann Rheum Dis 2007; 66: 34-45.

61 Braun J, Brandt J, Listing J, et al. Treatment of active ankylosing spondylitis with infliximab: a randomised controlled multicentre trial. Lancet 2002; 359: 1187-1193.

62 Braun J, Baraliakos X, Listing J, et al. Persistent clinical efficacy and safety of anti-tumour necrosis factor alpha therapy with infliximab in patients with ankylosing spondylitis over 5 years: evidence for different types of response. Ann Rheum Dis 2008; 67: 340-345.

63 McLeod C, Bagust A, Boland A, et al. Adalimumab, etanercept and infliximab for the treatment of ankylosing spondylitis: a systematic review and economic evaluation. Health Technol Assess 2007; 11: 1-158, iii-iv.

64 van der Heijde D, Landewe R, Einstein S, et al. Radiographic progression of ankylosing spondylitis after up to two years of treatment with etanercept. Arthritis Rheum 2008; 58: 1324-1331.

65 van der Heijde D, Landewe R, Baraliakos X, et al. Radiographic findings following two years of infliximab therapy in patients with ankylosing spondylitis. Arthritis Rheum 2008; 58: 3063-3070.

66 Woolacott NF, Khadjesari ZC, Bruce IN, et al. Etanercept and infliximab for the treatment of psoriatic arthritis: a systematic review. Clin Exp Rheumatol 2006; 24: 587-593.

67 Lovell DJ, Ruperto N, Goodman S, et al. Adalimumab with or without methotrexate in juvenile rheumatoid arthritis. $N$ Engl J Med 2008; 359: 810-820.

68 Tynjäla $\mathrm{P}$, Vähäsalo $\mathrm{P}$, Honkanen $\mathrm{V}$, et al. Drug survival of the first and second course of anti-tumour necrosis factor agents in juvenile idiopathic arthritis. Ann Rheum Dis 2009; 68: 552-557.

69 Russo RA, Katsicas MM. Clinical remission in patients with systemic juvenile idiopathic arthritis treated with anti-tumor necrosis factor agents. J Rheumatol 2009; 36: 1078-1082.

70 Targan SR, Hanauer SB, van Deventer SJ, et al. A short-term study of chimeric monoclonal antibody $\mathrm{CA} 2$ to tumor necrosis factor alpha for Crohn's disease. Crohn's Disease cA2 Study Group. N Engl J Med 1997; 337: 1029-1035.

71 Hanauer SB, Feagan BG, Lichtenstein GR, et al. Maintenance infliximab for Crohn's disease: the ACCENT I randomised trial. Lancet 2002; 359: 1541-1549.

72 Rutgeerts P, Sandborn WJ, Feagan BG, et al. Infliximab for induction and maintenance therapy for ulcerative colitis. $N$ Engl J Med 2005; 353: 2462-2476.

73 Colombel JF, Sandborn WJ, Rutgeerts P, et al. Adalimumab for maintenance of clinical response and remission in patients with Crohn's disease: the CHARM trial. Gastroenterology 2007; 132 52-65.

74 Schreiber S, Khaliq-Kareemi M, Lawrance IC, et al. Maintenance therapy with certolizumab pegol for Crohn's disease. N Engl J Med 2007; 357: 239-250.

75 Sandborn WJ, Feagan BG, Stoinov S, et al. Certolizumab pegol for the treatment of Crohn's disease. N Engl J Med 2007; 357: 228238.

76 Colombel JF, Sandborn WJ, Reinisch W, et al. Infliximab, azathioprine, or combination therapy for Crohn's disease. $N$ Engl J Med 2010; 362: 1383-1395.

77 Groves RW, Allen MH, Ross EL, et al. Tumour necrosis factor alpha is pro-inflammatory in normal human skin and modulates 
cutaneous adhesion molecule expression. Br J Dermatol 1995; 132: 345-352.

78 Smith $\mathrm{CH}$, Anstey AV, Barker JN, et al. British Association of Dermatologists' guidelines for biologic interventions for psoriasis 2009. Br J Dermatol 2009; 161: 987-1019.

79 Oh CJ, Das KM, Gottlieb AB. Treatment with anti-tumor necrosis factor alpha (TNF-alpha) monoclonal antibody dramatically decreases the clinical activity of psoriasis lesions. J Am Acad Dermatol 2000; 42: 829-830.

80 Menter A, Feldman SR, Weinstein GD, et al. A randomized comparison of continuous vs. intermittent infliximab maintenance regimens over 1 year in the treatment of moderate-to-severe plaque psoriasis. J Am Acad Dermatol 2007; 56: 31 e1-e15.

81 Dalaker M, Bonesronning JH. Long-term maintenance treatment of moderate-to-severe plaque psoriasis with infliximab in combination with methotrexate or azathioprine in a retrospective cohort. J Eur Acad Dermatol Venereol 2009; 23: 277-282.

82 Pink AE, Fonia A, Allen $\mathrm{MH}$, et al. Antinuclear antibodies associate with loss of response to anti-TNF alpha therapy in psoriasis: a retrospective, observational study. $\mathrm{Br} J$ Dermatol 2009; 162: 780-785.

83 Reich K, Nestle FO, Papp K, et al. Infliximab induction and maintenance therapy for moderate-to-severe psoriasis: a phase III, multicentre, double-blind trial. Lancet 2005; 366: 1367-1374.

84 Routhouska SB, Sheth PB, Korman NJ. Long-term management of generalized pustular psoriasis with infliximab: case series. J Cutan Med Surg 2008; 12: 184-188.

85 Collamer AN, Guerrero KT, Henning JS, et al. Psoriatic skin lesions induced by tumor necrosis factor antagonist therapy: a literature review and potential mechanisms of action. Arthritis Rheum 2008; 59: 996-1001.

86 Rich P, Griffiths CE, Reich K, et al. Baseline nail disease in patients with moderate to severe psoriasis and response to treatment with infliximab during 1 year. J Am Acad Dermatol 2008; 58: 224-231.

87 Leonardi CL, Powers JL, Matheson RT, et al. Etanercept as monotherapy in patients with psoriasis. N Engl J Med 2003; 349: 2014-2022.

88 Paller AS, Siegfried EC, Langley RG, et al. Etanercept treatment for children and adolescents with plaque psoriasis. N Engl J Med 2008; 358: 241-251.

89 Gordon KB, Langley RG, Leonardi C, et al. Clinical response to adalimumab treatment in patients with moderate to severe psoriasis: double-blind, randomized controlled trial and openlabel extension study. J Am Acad Dermatol 2006; 55: 598-606.

90 Menter A, Tyring SK, Gordon K, et al. Adalimumab therapy for moderate to severe psoriasis: a randomized, controlled phase III trial. J Am Acad Dermatol 2008; 58: 106-115.

91 Ryan C, Kirby B, Collins P, et al. Adalimumab treatment for severe recalcitrant chronic plaque psoriasis. Clin Exp Dermatol 2009; 34: 784-788.

92 Papoutsaki M, Chimenti MS, Costanzo A, et al. Adalimumab for severe psoriasis and psoriatic arthritis: an open-label study in 30 patients previously treated with other biologics. J Am Acad Dermatol 2007; 57: 269-275.

93 Wollina U, Hansel G, Koch A, et al. Tumor necrosis factor-alpha inhibitor-induced psoriasis or psoriasiform exanthemata: first 120 cases from the literature including a series of six new patients. Am J Clin Dermatol 2008; 9: 1-14.

94 Harrison MJ, Dixon WG, Watson KD, et al. Rates of new-onset psoriasis in patients with rheumatoid arthritis receiving antitumour necrosis factor alpha therapy: results from the British Society for Rheumatology Biologics Register. Ann Rheum Dis 2009; 68: 209-215.

95 Giamarellos-Bourboulis EJ, Pelekanou E, Antonopoulou A, et al. An open-label phase II study of the safety and efficacy of etanercept for the therapy of hidradenitis suppurativa. $\mathrm{Br} J$ Dermatol 2008; 158: 567-572.

96 Stagaki E, Mountford WK, Lackland DT, et al. The treatment of lupus pernio: results of 116 treatment courses in 54 patients. Chest 2009; 135: 468-476.

97 Reguiai Z, Grange F. The role of anti-tumor necrosis factor-alpha therapy in Pyoderma gangrenosum associated with inflammatory bowel disease. Am J Clin Dermatol 2007; 8: 67-77.

98 Brassard P, Lowe AM, Bernatsky S, et al. Rheumatoid arthritis, its treatments, and the risk of tuberculosis in Quebec, Canada. Arthritis Rheum 2009; 61: 300-304.

99 Yamada T, Nakajima A, Inoue E, et al. Increased risk of tuberculosis in patients with rheumatoid arthritis in Japan. Ann Rheum Dis 2006; 65: 1661-1663.

100 Seong SS, Choi CB, Woo JH, et al. Incidence of tuberculosis in Korean patients with rheumatoid arthritis (RA): effects of RA itself and of tumor necrosis factor blockers. J Rheumatol 2007; 34: 706-711.

101 Carmona L, Hernandez-Garcia C, Vadillo C, et al. Increased risk of tuberculosis in patients with rheumatoid arthritis. J Rheumatol 2003; 30: 1436-1439.

102 Lin PL, Plessner HL, Voitenok NN, et al. Tumor necrosis factor and tuberculosis. J Investig Dermatol Sym Proc 2007; 12: 22-25.

103 Adams LB, Mason CM, Kolls JK, et al. Exacerbation of acute and chronic murine tuberculosis by administration of a tumor necrosis factor receptor-expressing adenovirus. J Infect Dis 1995; 171: 400-405.

104 Botha T, Ryffel B. Reactivation of latent tuberculosis infection in TNF-deficient mice. J Immunol 2003; 171: 3110-3118.

105 Brassard P, Kezouh A, Suissa S. Antirheumatic drugs and the risk of tuberculosis. Clin Infect Dis 2006; 43: 717-722.

106 Tubach F, Salmon D, Ravaud P, et al. Risk of tuberculosis is higher with anti-tumor necrosis factor monoclonal antibody therapy than with soluble tumor necrosis factor receptor therapy: the three-year prospective French Research Axed on Tolerance of Biotherapies registry. Arthritis Rheum 2009; 60: 1884-1894.

107 Fonseca JE, Canhao H, Silva C, et al. Tuberculosis in rheumatic patients treated with tumour necrosis factor alpha antagonists: the Portuguese experience. Acta Reumatol Port 2006; 31: 247-253.

108 Mines D, Novelli L. Antirheumatic drugs and the risk of tuberculosis. Clin Infect Dis 2007; 44: 619-620.

109 Subramanyan GS, Yokoe DS, Sharnprapai S, et al. Using automated pharmacy records to assess the management of tuberculosis. Emerg Infect Dis 1999; 5: 788-791.

110 Fonseca JE, Canhao H, Silva C, et al. [Tuberculosis in rheumatic patients treated with tumour necrosis factor alpha antagonists: the Portuguese experience.] Acta Reumatol Port 2006; 31: 247-253.

111 Dixon WG, Hyrich KL, Watson KD, et al. Drug-specific risk of tuberculosis in patients with rheumatoid arthritis treated with anti-TNF therapy: results from the British Society for Rheumatology Biologics Register (BSRBR). Ann Rheum Dis 2010; 69: 522-528.

112 Winthrop KL, Yamashita S, Beekmann SE, et al. Mycobacterial and other serious infections in patients receiving anti-tumor necrosis factor and other newly approved biologic therapies: case finding through the Emerging Infections Network. Clin Infect Dis 2008; 46: 1738-1740.

113 British Thoracic Society Standards of Care Committee. BTS recommendations for assessing risk and for managing Mycobacterium tuberculosis infection and disease in patients due to start anti-TNF-alpha treatment. Thorax 2005; 60: 800-805.

114 Centers for Disease Control and Prevention. Tuberculosis associated with blocking agents against tumor necrosis factoralpha: California, 2002-2003. MMWR Morb Mortal Wkly Rep 2004; 53: 683-686. 
115 Carmona L, Gomez-Reino JJ, Rodriguez-Valverde V, et al. Effectiveness of recommendations to prevent reactivation of latent tuberculosis infection in patients treated with tumor necrosis factor antagonists. Arthritis Rheum 2005; 52: 1766-1772.

116 Mariette $X$, Salmon D. French guidelines for diagnosis and treating latent and active tuberculosis in patients with RA treated with TNF blockers. Ann Rheum Dis 2003; 62: 791.

117 Kavanagh PM, Gilmartin JJ, O'Donnell J, et al. Tumour necrosis factor-alpha and tuberculosis: guidance from the National TB Advisory Committee. Ir Med J 2008; 101: 6-7.

118 Valesini G, Montecucco C, Cutolo M. Recommendations for the use of biologic (TNF-alpha blocking) agents in the treatment of rheumatoid arthritis in Italy. Clin Exp Rheumatol 2006; 24: 413-423.

119 Ponce de Leon D, Acevedo-Vasquez E, Sanchez-Torres A, et al. Attenuated response to purified protein derivative in patients with rheumatoid arthritis: study in a population with a high prevalence of tuberculosis. Ann Rheum Dis 2005; 64: 1360-1361.

120 Villiger PM, Zellweger JP, Moller B. Novel screening tools for latent tuberculosis: time to leave an old friend? Curr Opin Rheumatol 2009; 21: 238-243.

121 Raval A, Akhavan-Toyserkani G, Brinker A, et al. Brief communication: characteristics of spontaneous cases of tuberculosis associated with infliximab. Ann Intern Med 2007; 147: 699-702.

122 Barry CE 3rd, Boshoff HI, Dartois V, et al. The spectrum of latent tuberculosis: rethinking the biology and intervention strategies. Nature Rev Microbiol 2009; 7: 845-855.

123 Kaufmann SH. How can immunology contribute to the control of tuberculosis? Nat Rev Immunol 2001; 1: 20-30.

124 Mack U, Migliori GB, Sester M, et al. LTBI: latent tuberculosis infection or lasting immune responses to M. tuberculosis? A TBNET consensus statement. Eur Respir J 2009; 33: 956-973.

125 von Pirquet C. Die Allergieprobe zur Diagnose der Tuberkulose im Kindesalter. Wien Med Wochenschr 1907; 57: 1370-1374.

126 Sokal JE. Editorial: measurement of delayed skin-test responses. N Engl J Med 1975; 293: 501-502.

127 Andersen P, Munk ME, Pollock JM, et al. Specific immune-based diagnosis of tuberculosis. Lancet 2000; 356: 1099-1104.

128 Lalvani A, Pathan AA, McShane H, et al. Rapid detection of Mycobacterium tuberculosis infection by enumeration of antigenspecific T cells. Am J Respir Crit Care Med 2001; 163: 824-828.

129 Vincenti D, Carrara S, Butera O, et al. Response to region of difference 1 (RD1) epitopes in human immunodeficiency virus (HIV)-infected individuals enrolled with suspected active tuberculosis: a pilot study. Clin Exp Immunol 2007; 150: 91-98.

130 Mazurek GH, LoBue PA, Daley CL, et al. Comparison of a wholeblood interferon gamma assay with tuberculin skin testing for detecting latent Mycobacterium tuberculosis infection. JAMA 2001; 286: $1740-1747$.

131 Goletti D, Butera O, Bizzoni F, et al. Region of difference 1 antigen-specific CD4+ memory T cells correlate with a favorable outcome of tuberculosis. J Infect Dis 2006; 194: 984-992.

132 Dinser R, Fousse M, Sester U, et al. Evaluation of latent tuberculosis infection in patients with inflammatory arthropathies before treatment with TNF-alpha blocking drugs using a novel flow-cytometric interferon-gamma release assay. Rheumatology (Oxford) 2008; 47: 212-218.

133 Sester M, Sester U, Clauer P, et al. Tuberculin skin testing underestimates a high prevalence of latent tuberculosis infection in hemodialysis patients. Kidney Int 2004; 65: 1826-1834.

134 Sester U, Junker $\mathrm{H}$, Hodapp $\mathrm{T}$, et al. Improved efficiency in detecting cellular immunity towards $M$. tuberculosis in patients receiving immunosuppressive drug therapy. Nephrol Dial Transplant 2006; 21: 3258-3268.

135 Mahairas GG, Sabo PJ, Hickey MJ, et al. Molecular analysis of genetic differences between Mycobacterium bovis BCG and virulent M. bovis. J Bacteriol 1996; 178: 1274-1282.
136 Gey van Pittius NC, Sampson SL, Lee H, et al. Evolution and expansion of the Mycobacterium tuberculosis PE and PPE multigene families and their association with the duplication of the ESAT-6 (esx) gene cluster regions. BMC Evol Biol 2006; 6: 95.

137 Lalvani A, Millington KA. T cell-based diagnosis of childhood tuberculosis infection. Curr Opin Infect Dis 2007; 20: 264-271.

138 Huebner RE, Schein MF, Bass JB Jr. The tuberculin skin test. Clin Infect Dis 1993; 17: 968-975.

139 Pai M, Zwerling A, Menzies D. Systematic review: T-cell-based assays for the diagnosis of latent tuberculosis infection: an update. Ann Intern Med 2008; 149: 177-184.

140 Pai M, Menzies D. The new IGRA and the old TST: making good use of disagreement. Am J Respir Crit Care Med 2007; 175: 529531.

141 Menzies D, Pai M, Comstock G. Meta-analysis: new tests for the diagnosis of latent tuberculosis infection: areas of uncertainty and recommendations for research. Ann Intern Med 2007; 146: 340-354.

142 Lalvani A, Pathan AA, Durkan H, et al. Enhanced contact tracing and spatial tracking of Mycobacterium tuberculosis infection by enumeration of antigen-specific T cells. Lancet 2001; 357: 20172021.

143 Cobanoglu N, Ozcelik U, Kalyoncu U, et al. Interferon-gamma assays for the diagnosis of tuberculosis infection before using tumour necrosis factor-alpha blockers. Int J Tuberc Lung Dis 2007, 11: 1177-1182.

144 Matulis G, Juni P, Villiger PM, et al. Detection of latent tuberculosis in immunosuppressed patients with autoimmune diseases: performance of a Mycobacterium tuberculosis antigenspecific interferon gamma assay. Ann Rheum Dis 2008; 67: 84-90.

145 Ponce de Leon D, Acevedo-Vasquez E, Alvizuri S, et al. Comparison of an interferon-gamma assay with tuberculin skin testing for detection of tuberculosis (TB) infection in patients with rheumatoid arthritis in a TB-endemic population. J Rheumatol 2008; 35: 776-781.

146 Vassilopoulos D, Stamoulis N, Hadziyannis E, et al. Usefulness of enzyme-linked immunospot assay (elispot) compared to tuberculin skin testing for latent tuberculosis screening in rheumatic patients scheduled for anti-tumor necrosis factor treatment. J Rheumatol 2008; 35: 1271-1276.

147 Bocchino M, Matarese A, Bellofiore B, et al. Performance of two commercial blood IFN-gamma release assays for the detection of Mycobacterium tuberculosis infection in patient candidates for anti-TNF-alpha treatment. Eur J Clin Microbiol Infect Dis 2008; 27: 907-913.

148 Bartalesi F, Vicidomini S, Goletti D, et al. QuantiFERON-TB Gold and the TST are both useful for latent tuberculosis infection screening in autoimmune diseases. Eur Respir J 2009; 33: 586-593.

149 Murakami S, Takeno M, Kirino Y, et al. Screening of tuberculosis by interferon-gamma assay before biologic therapy for rheumatoid arthritis. Tuberculosis (Edinb) 2009; 89: 136-141.

150 Martin J, Walsh C, Gibbs A, et al. Comparison of interferon- $\gamma-$ release assays and conventional screening tests before tumour necrosis factor- $\alpha$ blockade in patients with inflammatory arthritis. Ann Rheum Dis 2010; 69: 181-185.

151 Behar SM, Shin DS, Maier A, et al. Use of the T-SPOT.TB assay to detect latent tuberculosis infection among rheumatic disease patients on immunosuppressive therapy. J Rheumatol 2009; 36: 546-551.

152 Laffitte E, Janssens JP, Roux-Lombard P, et al. Tuberculosis screening in patients with psoriasis before antitumour necrosis factor therapy: comparison of an interferon-gamma release assay vs. tuberculin skin test. Br J Dermatol 2009; 161: 797-800.

153 Soborg B, Ruhwald M, Hetland ML, et al. Comparison of screening procedures for Mycobacterium tuberculosis infection among patients with inflammatory diseases. J Rheumatol 2009; 36: 1876-1884. 
154 Inanc N, Aydin SZ, Karakurt S, et al. Agreement between Quantiferon-TB gold test and tuberculin skin test in the identification of latent tuberculosis infection in patients with rheumatoid arthritis and ankylosing spondylitis. I Rheumatol 2009; 36: 2675-2681.

155 Aichelburg MC, Rieger A, Breitenecker F, et al. Detection and prediction of active tuberculosis disease by a whole-blood interferon-gamma release assay in HIV-1-infected individuals. Clin Infect Dis 2009; 48: 954-962.

156 Rieder HL. Epidemiologic basis of tuberculosis control. Paris, International Union Against Tuberculosis and Lung Disease, 1999.

157 Anon. Targeted tuberculin testing and treatment of latent tuberculosis infection. Am J Respir Crit Care Med 2000; 161: S221-S247.

158 Joint Tuberculosis Committee of the British Thoracic Society. Control and prevention of tuberculosis in the United Kingdom: Code of Practice 2000. Thorax 2000; 55: 887-901.

159 Belknap $R$, Reves $R$, Burman W. Immune reconstitution to Mycobacterium tuberculosis after discontinuing infliximab. Int J Tuberc Lung Dis 2005; 9: 1057-1058.

160 Garcia Vidal C, Rodriguez Fernandez S, Martinez Lacasa J, et al. Paradoxical response to antituberculous therapy in infliximabtreated patients with disseminated tuberculosis. Clin Infect Dis 2005; 40: 756-759.

161 Gerloni V, Pontikaki I, Gattinara M, et al. Focus on adverse events of tumour necrosis factor alpha blockade in juvenile idiopathic arthritis in an open monocentric long-term prospective study of 163 patients. Ann Rheum Dis 2008; 67: 1145-1152.

162 Dekker L, Armbrust W, Rademaker CM, et al. Safety of antiTNFalpha therapy in children with juvenile idiopathic arthritis. Clin Exp Rheumatol 2004; 22: 252-258.

163 Horneff G, De Bock F, Foeldvari I, et al. Safety and efficacy of combination of etanercept and methotrexate compared to treatment with etanercept only in patients with juvenile idiopathic arthritis (JIA): preliminary data from the German JIA Registry. Ann Rheum Dis 2009; 68: 519-525.

164 Prince $\mathrm{FH}$, Twilt $\mathrm{M}$, ten Cate $\mathrm{R}$, et al. Long-term follow-up on effectiveness and safety of etanercept in juvenile idiopathic arthritis: the Dutch national register. Ann Rheum Dis 2009; 68: 635-641.

165 Lovell DJ, Reiff A, Ilowite NT, et al. Safety and efficacy of up to eight years of continuous etanercept therapy in patients with juvenile rheumatoid arthritis. Arthritis Rheum 2008; 58: 1496-1504.

166 Myers A, Clark J, Foster H. Tuberculosis and treatment with infliximab. N Engl J Med 2002; 346: 623-626.

167 Armbrust W, Kamphuis SS, Wolfs TW, et al. Tuberculosis in a nine-year-old girl treated with infliximab for systemic juvenile idiopathic arthritis. Rheumatology (Oxford) 2004; 43: 527-529.

168 Veres G, Baldassano RN, Mamula P. Infliximab therapy in children and adolescents with inflammatory bowel disease. Drugs 2007; 67: 1703-1723.
169 Hyams JS, Lerer T, Griffiths A, et al. Long-term outcome of maintenance infliximab therapy in children with Crohn's disease. Inflamm Bowel Dis 2009; 15: 816-822.

170 Ruperto N, Lovell DJ, Cuttica R, et al. A randomized, placebocontrolled trial of infliximab plus methotrexate for the treatment of polyarticular-course juvenile rheumatoid arthritis. Arthritis Rheum 2007; 56: 3096-3106.

171 Ilowite NT. Update on biologics in juvenile idiopathic arthritis. Curr Opin Rheumatol 2008; 20: 613-618.

172 Newton SM, Brent AJ, Anderson S, et al. Paediatric tuberculosis. Lancet Infect Dis 2008; 8: 498-510.

173 Kampmann B, Whittaker E, Williams A, et al. Interferon- $\gamma$ release assays do not identify more children with active tuberculosis than the tuberculin skin test. Eur Respir J 2009; 33: 1374-1382.

174 Taylor RE, Cant AJ, Clark JE. Potential effect of NICE tuberculosis guidelines on paediatric tuberculosis screening. Arch Dis Child 2008; 93: 200-203.

175 Detjen AK, Keil T, Roll S, et al. Interferon-gamma release assays improve the diagnosis of tuberculosis and nontuberculous mycobacterial disease in children in a country with a low incidence of tuberculosis. Clin Infect Dis 2007; 45: 322-328.

176 Haustein T, Ridout DA, Hartley JC, et al. The likelihood of an indeterminate test result from a whole-blood interferon-gamma release assay for the diagnosis of Mycobacterium tuberculosis infection in children correlates with age and immune status. Pediatr Infect Dis J 2009; 28: 669-673.

177 Diel R, Hauer B, Loddenkemper R, et al. [Recommendations for tuberculosis screening before initiation of TNF-alpha-inhibitor treatment in rheumatic diseases.] Pneumologie 2009; 63: 329-334.

178 Furst DE, Cush J, Kaufmann S, et al. Preliminary guidelines for diagnosing and treating tuberculosis in patients with rheumatoid arthritis in immunosuppressive trials or being treated with biological agents. Ann Rheum Dis 2002; 61: Suppl. 2, ii62-ii63.

179 Salmon D. Recommendations about the prevention and management of tuberculosis in patients taking infliximab. Joint Bone Spine 2002; 69: 170-172.

180 Sociedad Espanola Reumatologia. Actualizacion de la guia de practica clinica para el manejo de la arthritis reumatoide en Espana. 2007. www.ser.es/ArchivosDESCARGABLES/Proyectos/ GUIPCAR_2007/GUIPCAR2007-Completa.pdf.

181 Pache I, Rogler G, Felley C. TNF-alpha blockers in inflammatory bowel diseases: practical consensus recommendations and a user's guide. Swiss Med Wkly 2009; 139: 278-287.

182 Sellam J, Hamdi H, Roy C, et al. Comparison of in vitro-specific blood tests with tuberculin skin test for diagnosis of latent tuberculosis before anti-TNF therapy. Ann Rheum Dis 2007; 66: 1610-1615.

183 Centers for Disease Control and Prevention (CDC). Update: fatal and severe liver injuries associated with rifampin and pyrazinamide for latent tuberculosis infection, and revisions in American Thoracic Society/CDC recommendations: United States, 2001. MMWR Morb Mortal Wkly Rep 2001; 50: 733-735. 